\title{
Domestic oil and gas or imported oil and gas - An energy return on investment perspective
}

Cheng Cheng ${ }^{a}$, Zhen Wang ${ }^{b, *}$, Jianliang Wang ${ }^{c}$, Mingming Liu ${ }^{b}$, Xiaohang Ren ${ }^{\mathrm{d}}$

\author{
${ }^{\text {a }}$ School of Management Science and Engineering, Shanxi University of Finance and Economics, 696 \\ Wucheng Road, Taiyuan City, Shanxi Province, 030006 China \\ ${ }^{\mathrm{b}}$ Academy of Chinese Energy Strategy, China University of Petroleum-Beijing, 18 Fuxue Road, \\ Changping, Beijing, 102249, China \\ ${ }^{\mathrm{c}}$ School of Business Administration, China University of Petroleum-Beijing, 18 Fuxue Road, \\ Changping, Beijing, 102249, China \\ ${ }^{\mathrm{d}}$ School of Mathematical Sciences, University of Southampton, Southampton SO17 1BJ, UK
}

\begin{abstract}
Both domestic oil and gas and imported oil and gas are essential to meet the enormous energy demand in China, which is incurred by its rapid economic growth. However, which is better than another? To address this issue, an energy return on investment (EROI) analysis, which is a useful method to evaluate the physical performance of an energy process, is applied. Besides, the EROIs time series of offshore domestic oil and gas and onshore domestic oil and gas are calculated, and the causes of the change tendency of EROIs time series are studied. The EROIs of imported oil and gas from different import countries are also calculated, laying the foundation for optimization of the import structure from an EROI perspective. Moreover, environmental inputs, which cause the externality of an energy process, are also studied. The results show that the EROIs of the entire domestic oil and gas fluctuate between 8.5 and 12, and the EROIs of the imported oil and gas lie in the range
\end{abstract}


between 2.9 and 9.5. We conclude that: 1) The EROIs of domestic oil and gas is higher than those of imported oil and gas, indicating that domestic oil and gas has a higher physical efficiency than imported oil and gas. 2) The change tendency of EROIs is influenced by the extractions of natural gas. Moreover, the EROIs of imported oil and gas are additionally related to oil and gas prices. 3) From an EROI perspective, LNG and pipeline gas are better than imported crude oil. Australia, Kazakhstan, and the USA should be prioritized for China to import LNG, pipeline gas, and crude oil respectively. 4) Environmental inputs reduce the EROIs. Therefore more caution should be paid on the reduction of environmental inputs.

Keywords: Energy return on investment; Domestic oil and gas; Imported oil and gas; Optimization of import structure; environmental inputs

\section{Introduction}

Oil and gas (OG) play a pivotal role in the modern industry, and OG demand is closely related to economic development. China has seen rapid growth in the economy since the reform and openness. Meanwhile, the demand for OG in China has increased significantly due to the rapid economic growth (see Fig. 1). To satisfy the substantial growth, China has begun to push the development of its domestic OG industry and to import OG from other producers. However, the gap between domestic production and consumption will become larger in the future. BP estimates that the imported OG volume will double its size and reach 836 million tons oil equivalent (MTOE) in 2035 (BP, 2015), indicating that the average annual growth rate is approximate $5.5 \%$.

\section{$<$ Figure 1 Here >}

There are two ways to bridge the gap, namely domestic OG (DOG) and imported OG (IOG). The DOG is always a vital supply source for China. Although China does not belong to oil-rich countries, there are still some potentials - the proven OG reserves in 
China were 2.5 billion tons and 3.8 trillion cubic meters respectively in 2015 (BP, 2016).

IOG serves as another important supply source for China and accounts for a significant proportion in the supply mix. Domestic productions and key suppliers of IOG for China in 2014 are shown in Fig. 2.

$<$ Figure 2 here >

\begin{tabular}{|c|c|c|c|}
\hline Abbreviations & & & \\
\hline $\mathrm{A}_{I G}$ & $\begin{array}{l}\text { Aggregate volume of imported } \\
\text { gas }\end{array}$ & $\mathrm{ENV}_{O F D O G}$ & $\begin{array}{l}\text { Environmental inputs of offshore } \\
\text { DOG }\end{array}$ \\
\hline $\mathrm{A}_{I O}$ & Aggregate volume of imported oil & $E N V_{O N D O G}$ & $\begin{array}{l}\text { Environmental inputs of onshore } \\
\text { DOG }\end{array}$ \\
\hline $\mathrm{CNOOC}$ & $\begin{array}{l}\text { China National Offshore Oil } \\
\text { Corporation }\end{array}$ & EROI & Energy return on investment \\
\hline CNPC & $\begin{array}{l}\text { China National Petroleum } \\
\text { Corporation }\end{array}$ & $\mathrm{EROI}_{C O}$ & EROI of crude oil \\
\hline DDA & $\begin{array}{l}\text { Dismantlement and site } \\
\text { restoration allowance }\end{array}$ & $\mathrm{EROI}_{D O G}$ & EROI of the entire DOG \\
\hline $\mathrm{DEF}_{i}$ & $\begin{array}{l}\text { DOG emission factor of emission } \\
i\end{array}$ & $\mathrm{EROI}_{D O G, e n v}$ & $\begin{array}{l}\text { EROI with environmental inputs of } \\
\text { the entire DOG }\end{array}$ \\
\hline DOG & Domestic oil and gas & $\mathrm{EROI}_{I O}$ & EROI of imported oil \\
\hline $\mathrm{E}_{D O G}$ & Entire DOG energy outputs & $\mathrm{EROI}_{I G}$ & EROI of imported gas \\
\hline $\mathrm{E}_{O F D O G}$ & Offshore DOG energy outputs & $\mathrm{EROI}_{I O G}$ & EROI of IOG \\
\hline $\mathrm{E}_{O N D O G}$ & Onshore DOG energy outputs & $\mathrm{EROI}_{I O G, e n v}$ & $\begin{array}{l}\text { EROI with environmental inputs of } \\
\text { IOG }\end{array}$ \\
\hline $\mathrm{E}_{P(I G)}$ & Unit price of the imported gas & $\mathrm{EROI}_{L N G}$ & EROI of LNG \\
\hline $\mathrm{E}_{P(I O)}$ & Unit price of the imported oil & $\mathrm{EROI}_{N G}$ & EROI of natural gas \\
\hline $\mathrm{E}_{P(o i l)}$ & Price per barrel of oil & $\mathrm{EROI}_{O F D O G}$ & EROI of offshore DOG \\
\hline $\mathrm{E}_{U(I G)}$ & $\begin{array}{l}\text { Unit energy output of the } \\
\text { imported gas }\end{array}$ & EROI $_{O F D O G, e n v}$ & $\begin{array}{l}\text { EROI with environmental inputs of } \\
\text { offshore DOG }\end{array}$ \\
\hline $\mathrm{E}_{U(I O)}$ & $\begin{array}{l}\text { Unit energy output of the } \\
\text { imported oil }\end{array}$ & $\mathrm{EROI}_{O N D O G}$ & EROI of onshore DOG \\
\hline $\mathrm{E}_{U(\text { oil })}$ & Unit energy content of oil & $\mathrm{EROI}_{O N D O G, e n v}$ & $\begin{array}{l}\text { EROI with environmental inputs of } \\
\text { onshore DOG }\end{array}$ \\
\hline $\mathrm{E}_{T}$ & Total energy & $\mathrm{EROI}_{P G}$ & EROI of pipeline gas \\
\hline $\mathrm{E}_{d}$ & Direct inputs of the entire DOG & $\mathrm{EROI}_{\text {stnd }}$ & Standard EROI \\
\hline $\mathrm{E}_{\text {eint }}$ & $\begin{array}{l}\text { Energy intensity of the entire } \\
\text { economy }\end{array}$ & $\mathrm{EROI}_{1, e n v}$ & $\begin{array}{l}\text { Standard EROI with environmental } \\
\text { inputs }\end{array}$ \\
\hline $\mathrm{E}_{i d}$ & Indirect inputs of the entire DOG & GDP & Gross domestic production \\
\hline $\mathrm{E}_{\text {iint }}$ & $\begin{array}{l}\text { Energy intensity of industrial } \\
\text { sector }\end{array}$ & IOG & Imported oil and gas \\
\hline $\mathrm{E}_{o}$ & DOG energy outputs & LNG & Liquefied natural gas \\
\hline $\mathrm{ECF}_{i}$ & External cost factor of emission $i$ & $\mathrm{M}_{i d}$ & $\begin{array}{l}\text { Monetary indirect costs of the entire } \\
\text { DOG }\end{array}$ \\
\hline $\mathrm{EE}$ & Exploration expenses & $\mathrm{M}_{O F D O G}$ & Monetary inputs of offshore DOG \\
\hline $\mathrm{EF}_{i}$ & $\begin{array}{l}\text { Emission factor of emission } i \\
\text { related to IOG }\end{array}$ & $\mathrm{OE}$ & Operating expenses \\
\hline EJ & Exajoule & OG & Oil and gas \\
\hline $\mathrm{ENV}_{D O G}$ & $\begin{array}{l}\text { Environmental inputs of the entire } \\
\text { DOG }\end{array}$ & $\mathrm{PJ}$ & Petajoule \\
\hline $\mathrm{ENV}_{I O G}$ & IOG environmental inputs & SINOPEC & $\begin{array}{l}\text { China Petroleum \& Chemical } \\
\text { Corporation }\end{array}$ \\
\hline
\end{tabular}


China needs more OG to support its economic development, and care more about the energy surplus and physical efficiency of OG supply. Therefore, several interesting questions arise: from a physical efficiency perspective, which way to obtain the OG resources is better for China, DOG or IOG? How do the physical efficiencies of different energy supply processes (namely the entire DOG, the onshore DOG, the offshore DOG, and IOG) change over time, and what causes the change tendency? Which oil-exporting countries are excellent choices for China? Besides, as environmental issues receive great attention globally, and more energy inputs are required to eliminate the pollutions, environmental issues can be regarded as energy inputs of an energy supply process and have considerable impacts on EROI. Thus, another question is proposed: What will happen to EROIs when environmental inputs are considered?

An energy return on investment (EROI) analysis is proposed to address such questions from the perspective of net energy analysis. EROI is the ratio of the aggregate produced energy to the aggregate consumed energy in an energy supply process (Hall et al., 1979). It is different from economic indicators because it measures the energetic physical performance. Therefore, it is a useful and straightforward indicator which reflects the net energy surplus to the society (Gupta and Hall, 2011; Murphy et al., 2011). The concept originated from ecology (Hall, 1972), and was first formally proposed by Hall et al. (1979). Later on, several important papers were published in Science and other journals by Hall, Cleveland, Kaufmann and others (Cleveland et al., 1984; Hall et al., 1986; Hall and Cleveland, 1981). Few studies were carried out after that. However, studies on EROI have sprung up again after 2005.

Two basic methodologies are applied in the EROI analysis, i.e. the bottom-up and the top-down. The choice of the methodologies is determined by the system boundaries and data restriction (Murphy et al., 2011). For bottom-up methodology, process analysis is a typical and standardized method - it divides an energy supply process into several 
procedures and estimates the EROI by summing up the inputs and outputs of each procedure. Life cycle assessment (LCA) belongs to process analysis, (Murphy et al., 2016) suggest that all researchers should apply LCA when calculating EROI, which makes the comparison between different energy technologies consistent. However, LCA is limited by data availability. As for top-down methodology, the economic input-output analysis is a typical method, in which inputs and outputs are derived from economic data. The dynamic function is another example of top-down methodology (Dale et al., 2011a). Recently, a hybrid methodology combining process analysis and economic input-output analysis is proposed recently to overcome data restriction (Murphy et al., 2011).

The mainstream protocol in EROI analysis is proposed by Murphy et al. (2011). Before that, studies on EROI were divergent because there was no consensus about the system boundaries. A two-dimensional framework was presented by Murphy et al. (2011) to confine the system boundaries. Apart from this protocol, several other protocols were proposed (Arvesen and Hertwich, 2015; Atlason and Unnthorsson, 2014; Brandt et al., 2013; Brandt and Dale, 2011; Chen et al., 2017; Dale et al., 2011a; Feng et al., 2018; Hall et al., 2009; Henshaw et al., 2011; Kessides and Wade, 2011; Zhang and Colosi, 2013). Most of these protocols are similar to Murphy's or are based on Murphy's, despite the frameworks proposed by Dale et al. (2011a) and Henshaw et al. (2011). However, these two frameworks focus on the physical principles, which leads to the neglect of economic properties of the energy carriers.

EROI analysis is applied in three areas: 1) To measure the performance of different energy systems, which is the most common application. Energetic physical performance of different energy supply processes are evaluated by EROIs analysis, including oil and gas (Brandt, 2011; Brandt et al., 2015; Cleveland, 2005; Court and Fizaine, 2017; Dale et al., 2011b; Feng et al., 2018; Freise, 2011; Gagnon et al., 2009; Gately, 2007; Grandell et al., 2011; Guilford et al., 2011; Hall et al., 2014; Hu et al., 2011; Hu et al., 2013; Kong et al., 
2016; Moerschbaecher and Day Jr., 2011; Nogovitsyn and Sokolov, 2014; Poisson and Hall, 2013; Safronov and Sokolov, 2014; Xu et al., 2014), coal (Court and Fizaine, 2017; Feng et al., 2018; Hall et al., 2014; Hu et al., 2013), shale oil and gas (Cleveland and O Connor, 2011; Sell et al., 2011; Wang et al., 2017; Yaritani and Matsushima, 2014), oil sand (Brandt et al., 2013; Wang et al., 2017), power generation (including wind and solar power generation) (Dupont et al., 2018; Huang et al., 2017; Kittner et al., 2016; Kunz et al., 2014; Leccisi et al., 2016; Neumeyer and Goldston, 2016; Raugei et al., 2012; Raugei and Leccisi, 2016; Swenson, 2016; Weißbach et al., 2013), coal to liquid and gas (Kong et al., 2015; Kong et al., 2016), jet fuel (Trivedi et al., 2015), energy production sector (Brand-Correa et al., 2017; Feng et al., 2018), and biofuel (Beal et al., 2012; Font De Mora et al., 2012; Pechsiri et al., 2016). 2) To compare the impacts of technology and depletion. Technology will enhance the EROI by promoting the efficiency. However, depletion will decrease the EROI. Their impacts are examined by several scholars (Brandt, 2011; Brandt et al., 2013; Cleveland, 2005; Gagnon et al., 2009; Gately, 2007; Grandell et al., 2011; Guilford et al., 2011; Hall et al., 2014; Hu et al., 2011; Nogovitsyn and Sokolov, 2014; Poisson and Hall, 2013; Safronov and Sokolov, 2014; Sell et al., 2011). 3) To study the relationship between economy and EROI. Recently, the relationship between oil price, economic performance, and EROI receives more attention (Aucott and Hall, 2014; Heun and de Wit, 2012; King and Hall, 2011; Murphy and Hall, 2011).

Although previous studies have expanded the application fields of EROI analysis, little attention is paid to the comparison of EROIs of DOG process and IOG process in China, let alone the comparison of EROIs of offshore DOG and EROIs of onshore DOG and the causal analysis of the change tendency of different EROIs time series. Besides, the externalities (pollutions), which are generated during the OG production or trade processes and influence the energetic performance, are often neglected in the EROI analysis. Hu et al. (2013) calculated the EROIs of fossil fuels in China, but they overlooked the difference 
between the EROIs of onshore DOG and offshore DOG and the impacts of pollutions. To bridge the research gaps and to address the practical problems, we conduct EROI analyses compare the performance of DOG and IOG in China; to analyze the historical performance of DOG, offshore DOG, onshore DOG, and IOG; and to compare the performance of different IOG. Besides, the EROIs with environmental inputs are calculated to study the impacts of pollutions. This study has twofold meanings: 1) this study fill the gaps and extends the application areas of EROI analysis, and take environmental issues into consideration, which modifies standard EROI. 2) this study provide the policymakers with suggestions about the development of OG in China from an EROI perspective.

The layout of the rest of this paper is as follows. Section 2 discusses the methodology of DOG and IOG. Section 3 describes the calculation process of energy inputs and outputs of DOG. Section 4 describes the calculation process of energy inputs and outputs of IOG. In section 5, different EROIs are obtained, and the critical issues are discussed in this section. Section 6 provides the concluding remarks and policy recommendations.

\section{Methodology}

\subsection{Standard EROI and EROI with environmental inputs}

EROI is the ratio between the aggregate energy outputs and energy inputs of an energy process, to be specific, EROI is calculated by Equation (1):

$$
\text { EROI }=\frac{\text { Energy outputs }}{\text { Energy inputs }}
$$

Equation (1) is the basic concept of EROI.

EROI of an energy process is expressed by $\mathrm{x}$ : 1 , which indicates that $\mathrm{x}$ units energy are produced at the cost of 1 unit energy. Both the numerator and denominator are in energy units. Thus, EROI is a unitless indicator. Therefore, it is widely used to measure and compare the physical performance of different energy processes because of its convenience 
and straightforwardness. The baseline of EROI is 1, which indicates that the energy outputs are only enough to cover the energy inputs.

Identification of system boundaries is noteworthy, and two questions are closely related to the identification of system boundaries, namely, "what should be counted as inputs?" and "what should be counted as outputs?" (Murphy et al., 2011). To address these two questions, we apply the two-dimensional framework proposed by Murphy et al. (2011). Besides, we set the Chinese borderline as the physical boundaries in order to compare the EROIs of DOG and IOG. To be specific, regarding the DOG, we only consider the energy inputs and outputs in the extraction process, which is in line with the standard EROI $\left(\mathrm{EROI}_{\text {stnd }}\right)$ in Murphy's framework. As for IOG, we only consider the energy inputs and outputs related to exported goods and service production and international transportation from the $\mathrm{OG}$ exporters to China, and neglect the energies relative to domestic transportation and international transportation from China to importers. Pollution belongs to an external input of an energy process. To study the impacts of pollutions, standard EROI with environmental inputs $\left(\mathrm{EROI}_{1, e n v}\right)$ is estimated and serves as a sensitivity analysis.

\subsection{EROI of DOG}

\subsubsection{EROI estimation for the entire DOG}

The entire DOG EROI is meant to evaluate the energetic physical performance of entire DOG extraction industry. The system boundary is shown in Fig. 3. With reference to Murphy et al. (2011), energy outputs are determined by the extracted unprocessed OG, and energy inputs are divided into direct and indirect inputs. Due to the data restriction, we apply a hybrid methodology (process analysis and economic input-output analysis) to calculate the EROI (see other examples in Hu et al., 2013; Poisson and Hall, 2013): Direct inputs measure the physical energy inputs, including crude oil, gasoline, kerosene, diesel, fuel, liquefied petroleum gas, refinery gas, other petroleum products, natural gas, liquefied 
natural gas (LNG), heat, electricity, other energy and raw coal. Indirect inputs are the embodied energy of material inputs which are constructed offsite, such as equipment and instrument. Environmental inputs measure the energy inputs of greenhouse emissions, such as $\mathrm{CO}_{2}, \mathrm{CH}_{4}$, and $\mathrm{NO}_{\mathrm{X}}$.

\section{$<$ Figure 3 here >}

The EROIs of the entire DOG without environmental inputs $\left(\mathrm{EROI}_{D O G}\right)$ and the EROIs of the entire DOG with environmental inputs $\left(\mathrm{EROI}_{D O G, \text { env }}\right)$ are calculated by the following equations:

$$
\begin{gathered}
\mathrm{EROI}_{D O G}=\frac{\mathrm{E}_{D O G}}{\mathrm{E}_{d}+\mathrm{E}_{i d}}=\frac{\mathrm{E}_{D O G}}{\mathrm{E}_{d}+\mathrm{M}_{i d} \times \mathrm{E}_{i i n t}} \\
\mathrm{EROI}_{D O G, e n v}=\frac{\mathrm{E}_{D O G}}{\mathrm{E}_{d}+\mathrm{M}_{i d} \times \mathrm{E}_{i i n t}+\mathrm{ENV}_{D O G}}
\end{gathered}
$$

where $\mathrm{E}_{D O G}$ denotes the energy outputs of the entire DOG, $\mathrm{E}_{d}$ denotes the direct inputs of the entire DOG, $\mathrm{E}_{i d}$ denotes the indirect inputs of the entire DOG, $\mathrm{M}_{i d}$ denotes the monetary indirect costs of the entire DOG, $\mathrm{E}_{\text {iint }}$ denotes the energy intensity of the industrial sector, and $\mathrm{ENV}_{D O G}$ denotes the environmental inputs of the entire DOG. Equation (2) and (3) are used to calculate the standard EROI and the EROI with environmental inputs of the entire DOG.

\subsubsection{EROI estimation for the offshore DOG}

The offshore DOG EROI is meant to evaluate the physical efficiency of offshore OG extraction industry. The system boundary is shown in Fig. 4. The extracted OG is the outputs. As available inputs data is in monetary units, we apply the economic input-output method to calculate the energy inputs, see another example in Gagnon et al. (2009). We apply $\mathrm{E}_{\text {iint }}$ to convert the monetary inputs into energy units. Another challenge is the monetary inputs are not available for China National Petroleum Corporation (CNPC) and China Petroleum \& Chemical Corporation (SINOPEC). Considering that most offshore 
DOG are produced by China National Offshore Oil Corporation (CNOOC) and the CNOOC monetary inputs is the only available data, we assume that the unit offshore monetary input is same for CNOOC, CNPC, and SINOPEC. Then, we estimate the offshore DOG EROI based on CNOOC data.

$<$ Figure 4 here $>$

The EROIs of the offshore DOG without environmental inputs $\left(\mathrm{EROI}_{\text {OFDOG }}\right)$ and the EROIs of the offshore DOG with environmental inputs $\left(\mathrm{EROI}_{O F D O G, e n v}\right)$ are calculated by the follows equations:

$$
\begin{gathered}
\mathrm{EROI}_{O F D O G}=\frac{\mathrm{E}_{O F D O G}}{\mathrm{M}_{O F D O G} \times \mathrm{E}_{i i n t}} \\
\mathrm{EROI}_{O F D O G, \text { env }}=\frac{\mathrm{E}_{\text {OFDOG }}}{\mathrm{M}_{O F D O G} \times \mathrm{E}_{\text {iint }}+\mathrm{ENV}_{O F D O G}}
\end{gathered}
$$

where $\mathrm{E}_{\text {OFDOG }}$ denotes the energy outputs of offshore DOG, $\mathrm{M}_{\text {OFDOG }}$ denotes the monetary inputs of offshore DOG, $\mathrm{E}_{\text {iint }}$ denotes the energy intensity of the industrial sector, and $\mathrm{ENV}_{\text {OFDOG }}$ denotes the environmental inputs of offshore DOG. Equation (4) and (5) are used to calculate the standard EROI and the EROI with environmental inputs of offshore DOG.

\subsubsection{EROI estimation for the onshore DOG}

Energy outputs of onshore DOG are calculated based on the annual production data. Energy inputs of onshore DOG are calculated as the difference between the entire DOG's energy inputs and the offshore DOG's. Therefore, the EROIs of the onshore DOG without environmental inputs $\left(\mathrm{EROI}_{O N D O G}\right)$ and the EROIs of the onshore DOG with environmental inputs $\left(\mathrm{EROI}_{O N D O G, \text { env }}\right)$ are calculated by the follows equations:

$$
\mathrm{EROI}_{O N D O G}=\frac{\mathrm{E}_{O N D O G}}{\mathrm{E}_{D O G}-\mathrm{E}_{O F D O G}}
$$




$$
\mathrm{EROI}_{O N D O G, e n v}=\frac{\mathrm{E}_{O N D O G}}{\mathrm{E}_{D O G}-\mathrm{E}_{O F D O G}+\mathrm{ENV}_{O N D O G}}
$$

where $\mathrm{E}_{O N D O G}$ denotes the energy outputs of onshore DOG, $\mathrm{E}_{D O G}$ denotes the energy outputs of the entire DOG, $\mathrm{E}_{\text {OFDOG }}$ denotes the energy inputs of offshore DOG, and $\mathrm{ENV}_{\text {ONDOG }}$ denotes the onshore DOG environmental inputs. Equation (6) and (7) are used to calculate the standard EROI and the EROI with environmental inputs of onshore DOG.

\subsection{EROI of IOG}

EROI of IOG measures the energetic physical performance of IOG process. To be specific, it is the ratio between the energy content of the purchased OG and the energy content of OG embodied in goods and services which are required to generate the necessary foreign exchange. The system boundary is shown in Fig. 5. Energy inputs, which are usually derived from economic data, include the embodied energies of the exported goods and services and the energies for international transportation from OG exporters to China. Energy outputs are the imported OG. The first explicit method to estimate the IOG EROI was proposed by Kaufmann (Hall et al., 1986), in which EROI for imported oil $\left(\mathrm{EROI}_{I O}\right)$ is calculated as:

$$
\mathrm{EROI}_{I O}=\frac{\mathrm{E}_{U(\text { oil })}}{\left(\mathrm{E}_{T} / \mathrm{GDP}\right) \times \mathrm{E}_{P(o i l)}}
$$

where $\mathrm{E}_{U(\text { oil })}$ is the unit energy content of oil, $\mathrm{E}_{T}$ is the total energy, GDP is the gross domestic production, and $\mathrm{E}_{P(\text { oil })}$ is the price per barrel of oil. Equation (8) is used to calculate the EROI of IO by Kaufmann.

$<$ Figure 5 here $>$

With reference to Equation (8), the EROI of IOG without environmental inputs $\left(\mathrm{EROI}_{I O G}\right)$ and the EROI of IOG with environmental inputs $\left(\mathrm{EROI}_{I O G, \text { env }}\right)$ are calculated as follows: 


$$
\begin{gathered}
\mathrm{EROI}_{I O G}=\frac{\mathrm{E}_{U(I O)} \times \mathrm{A}_{I O}+\mathrm{E}_{U(I G)} \times \mathrm{A}_{I G}}{\mathrm{E}_{\text {eint }} \times\left(\mathrm{E}_{P(I O)} \times \mathrm{A}_{I O}+\mathrm{E}_{P(I G)} \times \mathrm{A}_{I G}\right)} \\
\mathrm{EROI}_{I O G, e n v}=\frac{\mathrm{E}_{U(I O)} \times \mathrm{A}_{I O}+\mathrm{E}_{U(I G)} \times \mathrm{A}_{I G}}{\mathrm{E}_{\text {eint }} \times\left(\mathrm{E}_{P(I O)} \times \mathrm{A}_{I O}+\mathrm{E}_{P(I G)} \times \mathrm{A}_{I G}\right)+\mathrm{ENV}_{I O G}}
\end{gathered}
$$

where $\mathrm{E}_{U(I O)}$ denotes the unit energy output of the imported oil (IO), $\mathrm{A}_{I O}$ denotes the aggregate volume of $\mathrm{IO}, \mathrm{E}_{U(I G)}$ denotes the unit energy output of the imported gas (IG), $\mathrm{A}_{I G}$ denotes the aggregate volume of $\mathrm{IG}, \mathrm{E}_{P(I O)}$ denotes the unit price of the IO, $\mathrm{E}_{P(I G)}$ denotes the unit price of the IG, $\mathrm{E}_{\text {eint }}$ denotes the energy intensity of the entire economy, and $\mathrm{ENV}_{I O G}$ denotes the environmental inputs of IOG. Equation (9) and (10) are used to calculate the standard EROI and the EROI with environmental inputs of IOG.

\subsection{Energy conversion and environmental inputs}

\subsubsection{Energy conversion}

Two types of energy unit conversion are applied in this paper according to the data type: 1) Energy equivalent is employed for physical data; 2) Energy intensity is applied to monetary data. Energy equivalent measures the average calorific value of an energy carrier. It is used to convert the physical units into energy units. The energy equivalent of common energies is listed in Table 1.

\section{$<$ Table 1 here >}

Energy intensity, which measures the energy consumptions (in energy units) per gross domestic product or value-added by sectors (in monetary units), is applied to convert monetary units into energy units. Data on the annual industrial added value of OG extraction industry is not intact, especially the data before 2006, so it is hard to calculate the energy intensity of OG extraction industry. Therefore, the $\mathrm{E}_{i i n t}$ is alternatively applied as OG extraction is a subcategory of the industrial sector, see other examples in Cleveland (2005), Hu et al. (2011) and $\mathrm{Hu}$ et al. (2013). However, the $\mathrm{E}_{\text {eint }}$ is employed to calculate 
the EROI of IOG and the environmental inputs because the two processes involve products of the primary, secondary and tertiary industry. The energy intensity of both the industrial sector and the entire economy are shown in Fig. 6. The $\mathrm{E}_{\text {iint }}$ is higher than the $\mathrm{E}_{\text {eint }}$ for two reasons: 1) China's economy highly depends on the industry. The industrial added value accounted for about 40\% during 2000 and 2014. 2) The industrial sector is featured with high energy intensity because many energy-intensive industries belong to the industrial sector, such as smelting and pressing of ferrous metals, manufacture of raw chemical materials and chemical products, and manufacture of non-metallic mineral products.

\section{$<$ Figure 6 here >}

\subsubsection{Environmental inputs}

Two methods are applied to calculate the environmental inputs due to the available data. Regarding DOG, the environmental inputs are computed on the basis of energy outputs. Li et al.(2013) estimate the greenhouse emission of dominant secondary energy in China, we use their results to calculate the environmental inputs of DOG. To be specific,

$$
\mathrm{ENV}=\sum_{i} \mathrm{E}_{o} \times \mathrm{DEF}_{i} \times \mathrm{ECF}_{i} \times \mathrm{E}_{e i n t}
$$

where $\mathrm{E}_{o}$ is the energy outputs of DOG (in energy units), $\mathrm{DEF}_{i}$ is the DOG emission factor of emission $i$ (with $\mathrm{kg} / \mathrm{MJ}$ as the unit), $\mathrm{ECF}_{i}$ denotes the external cost factor of emission $i$ (with $\mathrm{kg} / \$$ as the unit), and $\mathrm{E}_{\text {eint }}$ denotes the energy intensity of the entire economy. Equation (11) is used to calculate the environmental inputs of DOG.

As for IOG, the environmental inputs are derived from monetary data. Energy intensity, emission factors, and external costs are employed to calculate the environmental inputs. To be specific, it is calculated by Equation (12). 


$$
\mathrm{ENV}=\sum_{i} \mathrm{EF}_{i} \times \mathrm{ECF}_{i} \times \mathrm{E}_{\text {eint }}
$$

where $\mathrm{EF}_{i}$ denotes the emission factor of emission $i$ in the exports production process and OG international transportation process (with $\mathrm{kg} / \$, \mathrm{~kg} / \mathrm{t} \cdot \mathrm{km}$, or $\mathrm{kg} / \mathrm{m}^{3} \cdot \mathrm{km}$ as units), $\mathrm{ECF}_{i}$ denotes the external cost factor of emission $i$ (with $\mathrm{kg} / \$$ as the unit), and $\mathrm{E}_{\text {eint }}$ denotes the energy intensity of the entire economy. Equation (12) is used to calculate the environmental inputs of IOG.

\subsection{Data}

There are three data sources in our paper, and they are noted in each table of this paper (apart from tables which contain the calculated results by using raw data): 1) Chinese official databases, such as China Energy Statistical Yearbook, China Statistical Yearbook, China Marine Statistical Yearbook, and General Administration of Customs. They are authoritative. These data start from 1997 to 2014, and include the production of crude oil and natural gas, consumption of different energies and so on. 2) Published statistical yearbook by international OG companies, such as BP. They are reliable. These data start from 1988 to 2015, and are used to describe the historical relationship among OG production, consumption, net import and so on. 3) Parameters from other published articles, such as $\mathrm{DEF}_{i}, \mathrm{EF}_{i}$, and $\mathrm{ECF}_{i}$. These papers are published after strict peer-review. They are also reliable. These data are fixed data, and are chosen from lasted papers (including papers from 2013 to 2016).

\section{Energy outputs, energy inputs and environmental inputs of DOG}

\subsection{Energy outputs, energy inputs and environmental inputs of the entire DOG}

\subsubsection{Energy outputs of the entire DOG}


The raw data of entire DOG energy outputs are collected in China Statistical Yearbook. We use the energy equivalents of crude oil and natural gas in Table 1 to convert the physical units to energy units, and the results are listed in Table 2.

$<$ Table 2 here >

\subsubsection{Energy inputs of the entire DOG}

For direct inputs, we collected data from China Energy Statistical Yearbook, which provides the physical consumption of different energies in OG extraction industry. The raw data are listed in Table A1. We use energy equivalent to converting the raw data to energy units. As for the indirect inputs, we collected data from China Statistic Yearbook. With reference to Hu et al. (2013), items of "purchase of equipment and instruments" and "others expenses" in fixed assets investment are counted as the indirect inputs in our analysis (see more details in Table A2). $E_{\text {iint }}$ is applied to convert the monetary units to energy units. A sum of direct and indirect inputs are listed in Table 3.

$<$ Table 3 here >

\subsubsection{Environmental inputs of the entire DOG}

The entire DOG energy outputs are calculated in Section 3.1.1. The $\mathrm{DEF}_{i}$ is calculated by $\mathrm{Li}$ et al. (2013), and the $\mathrm{ECF}_{i}$ is obtained from Pa et al. (2013) (see details in Table A3). The annual exchange rate for each year from 1997 to 2014 is applied in the calculation, and it is obtained from China Statistical Yearbook. The entire DOG environmental inputs is then calculated by Equation (11) on the base of these parameters, and the results is shown in Fig. 7.

$<$ Figure 7 here >

3.2. Energy outputs, energy inputs and environmental inputs of the offshore DOG 
We apply the same method to calculate the offshore DOG energy outputs as we calculate the energy outputs of the entire DOG. Raw data of the output is collected from China Marine Statistical Yearbook. Energy equivalent is employed to convert the units, and the results are listed in Table 4.

$$
<\text { Table } 4 \text { here > }
$$

\subsubsection{Energy inputs of the offshore DOG}

As mentioned in Section 2.2.2, we estimate the offshore DOG energy inputs on the base of CNOOC data. Therefore, we collect the daily OG productions, operating expenses (OE), depreciation, depletion and amortization (including dismantlement and site restoration allowance, DDA), and exploration expenses (EE) from the CNOOC annual reports. OE, DDA, and EE are the annual monetary inputs for an oil company to extract OG resources, and they are converted to energy units by $E_{\text {iint }}$ (details are shown in Table A4). The CNOOC daily DOG productions are used to calculate the CNOOC production percentage in the whole offshore DOG (details are shown in Table A5). The offshore inputs is CNOOC inputs divided by production percentage (see Table 5).

$<$ Table 5 here >

\subsubsection{Environmental inputs of the offshore DOG}

We take the same procedure to calculate the environmental inputs of the offshore DOG as we calculate the environmental inputs of the entire DOG, and the result is shown in Fig. 8.

$<$ Figure 8 here >

\subsection{Energy outputs, energy inputs and environmental inputs of the onshore DOG}

\subsubsection{Energy outputs of the onshore DOG}


The onshore DOG raw data is obtained by subtracting the whole DOG production with offshore DOG production. Then, energy equivalent is used to convert the physical inputs to energy inputs. Results are shown in Table 6.

$<$ Table 6 here $>$

\subsubsection{Energy inputs of the onshore DOG}

The onshore DOG energy inputs are calculated by subtracting the entire DOG inputs with offshore DOG inputs, and the results are shown in Table 7.

$<$ Table 7 here >

\subsubsection{Environmental inputs of the onshore DOG}

We again apply the same approach to calculate the onshore DOG environmental inputs as we calculate the environmental inputs of the entire DOG, and it is shown in Fig. 9.

$<$ Figure 9 here >

\section{Energy outputs, energy inputs and environmental inputs of IOG}

\subsection{Energy outputs of IOG}

The IOG raw data is collected in China Statistical Yearbook and is converted to energy units by using the energy equivalent. The results are shown in Table 8.

$<$ Table 8 here >

\subsection{Energy inputs of IOG}

The IOG energy inputs are decided by the OG purchase costs, international transportation fees, exchange rate, and convention factor. The IOG monetary inputs are obtained from General Administration of Customs. The raw data is CIF price, which includes the international transportation fee. However, it is counted in US dollars. 
Therefore, the exchange rate is used in the calculation process. The results are shown in Table 9.

$<$ Table 9 here >

\subsection{Environmental inputs of $I O G$}

The IOG environmental inputs are calculated by Equation (12). The $\mathrm{EF}_{i}$ is obtained from Kong et al. (2016), LMT (2015), and Skone et al. (2014) (details are shown in Table A3). Another challenge arise when estimating the transportation distance. The transportation distances of crude oil tankers and LNG carriers are collected from a website which can estimate the distance between different ports. Pipeline distances are collected from Kong et al. (2016) (see details in Table A6). The average distance is used as the transportation distance. The IOG environmental inputs is shown in Fig. 10.

$<$ Figure 10 here >

\section{EROI results and discussions}

The EROIs of DOG, offshore DOG, onshore DOG, and IOG are shown in Fig. 11 (a). The EROIs which considers the environmental inputs are illustrated in Fig. 11 (b). Externalities are an interesting and valuable factor for EROI analysis for its economic value, rather than the energetic value (Murphy et al., 2011). It necessitates the extra monetary inputs to treat the pollutions or to purchase pollution control equipment or certified emission reductions. Therefore, it will decrease the EROI, which can be observed by comparing the Fig. 11 (a) and (b). Externalities' negative impacts on EROI is also observed in Kong et al. (2016).

< Figure 11 here >

Before we start to discuss the results, we compare our results with other scholars, which is shown in Fig. 12. We compare our results with the EROIs of global OG production (Gagnon et al., 2009) and the USA OG production (Cleveland, 2005), which 
can be seen in Fig. 12(a). The EROIs of China is lower than those of global and the USA. The development conditions in China is not good: lots of OG fields are located in mountains; the reservoir depth is also very large. Poor development conditions enlarge the energy inputs, leading to low EROIs. We also compare our results the EROIs of the USA imported crude oil (Palcher et al., 2008) and China imported crude oil (Lambert et al., 2014), which can be seen in Fig. 12(b). Our results are similar to that of Lambert's but are lower than that of the USA.

< Figure 12 here >

\subsection{EROIs analysis of DOG}

\subsubsection{EROIs analysis of the entire DOG}

$\mathrm{EROI}_{D O G}$ fluctuated in the range between 8.5 to 12.0 during this period. It rose a little in 1998, but kept decreasing until 2004, after that it started to grow in fluctuation. The trend of $\mathrm{EROI}_{D O G}$ is determined by the changes of natural gas production ratio, the natural gas EROI $\left(\mathrm{EROI}_{N G}\right)$, the crude oil EROI $\left(\mathrm{EROI}_{C O}\right)$, and the development changes of OG industry in China. In general, the EROIs of an energy process always tend to be high in the early stage, and then to decline along with the development. It is decided by both inputs and outputs of the process. Take crude oil as an example, the outputs of an oilfield always start to increase from 0 to peak production, keep for several years, and then decline. Meanwhile, the inputs are small in the early stage as oil are extracted by natural pressure, but start to increase in the mid and late stages because different measures, such as water injection, chemical flooding and gas flooding, are needed to enhance oil recovery. Moreover, the conventional oils have been developed for a long time and depleted a lot. Therefore, more and more unconventional oils are produced. Compared to that of conventional oil, the development of unconventional oil is much harder, and requires more sophisticated technology and monetary inputs, which decrease the EROI in return. 
Compared to the crude oil development, the natural gas development is still in the early stage, therefore, $\mathrm{EROI}_{N G}$ is in the growth stage, while EROI $\mathrm{E}_{C O}$ is in decline stage (Gupta and Hall, 2011). During the 9th five-year plan period (1996-2000) and 10th five-year plan period (2001-2005) in China, the Chinese government realized the importance of natural gas, and started to promote its development. For example, the Chinese government stated in the 9th and 10th five-year plan that China would increase the investment in exploration of both OG, aiming to enhance the production of both OG. However, as the development of natural gas is still in the early stage, its production ratio is small compared to that of oil. In 1997, the ratio of natural gas production to the entire OG production was only about $11.3 \%$. The promotion effects of $\mathrm{EROI}_{N G}$ on the $\mathrm{EROI}_{D O G}$ was not strong enough to offset the reduction effects of $\mathrm{EROI}_{C O}$, therefore, $\mathrm{EROI}_{D O G}$ decreased during 1997 and 2004. During the 11th five-year plan period (2006-2010) and 12th five-year plan period (2011-2015), the Chinese government still promote the development of $\mathrm{OG}$, especially the natural gas. Therefore, the natural gas production percentage kept increasing recently, and pushed the $\mathrm{EROI}_{D O G}$ to increase in fluctuation.

It is hard to decompose the DOG inputs into inputs of crude oil and natural gas because their inputs are mixed in the available data. Therefore, it is difficult to calculate the EROI $_{N G}$ and EROI $C O$. We alternatively studied the relationship between the energy inputs and EROIs. As we can see from Fig. 13(a), there is a negative correlation between growth rates of energy inputs and EROIs. We can infer that an increase in energy inputs could generally generate a decline in $\mathrm{EROI}_{D O G}$.

\subsubsection{EROIs analysis of offshore DOG and onshore DOG}

The trends of $\mathrm{EROI}_{O N D O G}$ and $\mathrm{EROI}_{O F D O G}$ are quite different. EROI $\mathrm{ENDOG}_{\text {ON }}$ fluctuated in the range between 8.2 and 13.5, and the its trend is similar to that of DOG because the onshore DOG is in a dominant position within the DOG supply mix. 
Meanwhile, EROI OFDOG $_{\text {ied }}$ in the range between 7.2 and 12.6. EROI OFDOG increased at first, then declined for several years, but rose a little in 2014. Overall, EROI $_{O F D O G}$ showed a decline tendency. This trend is caused by the development stage of offshore OG industry in China. The Chinese government always pay attention to the development of offshore OG. During the 9th five-year plan period, the Chinese government focused on the nearshore OG. Consequently, early exploration and development activities of offshore OG resources were conducted in the nearshore areas, whose costs were relative low. However, from the 10th five-year plan period, the Chinese government started to emphasize the development of deep-water resources, more and more deep-water resources were developed due to the promotion of offshore OG industry. The monetary inputs for deep-water fields are much larger than onshore and nearshore fields, which leads to the EROI $_{O F D O G}$ decline. The promotion of offshore OG industry is reflected by the increasing monetary inputs of offshore DOG. As we can see from Fig. 13(b), the monetary inputs is negatively correlated with $\mathrm{EROI}_{O F D O G}$, and has a growth tendency in recent years.

\subsubsection{The overall analysis of DOG}

Although the trends of $\mathrm{EROI}_{D O G}$ and $\mathrm{EROI}_{O N D O G}$ are similar, there is still a difference between them, especially before 2004 and after 2009. The difference is caused by the offshore OG production percentage and the EROI trends. To be specific, although

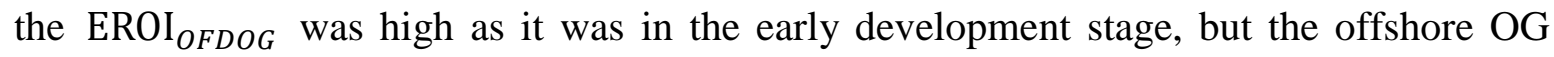
only accounted for about $14 \%$ before 2004. On the other hand, the onshore DOG production overwhelmed the offshore DOG production despite of the low EROI ONDOG $_{\text {. }}$ These two features made the difference between $\mathrm{EROI}_{D O G}$ and $\mathrm{EROI}_{O F D O G}$ was positive and small. While after 2009, due to development guidance of offshore OG by the Chinese government, the production percentage of the offshore DOG became high, which reached to $18 \%$, but the $\mathrm{EROI}_{O F D O G}$ became smaller than $\mathrm{EROI}_{O N D O G}$ because of the difficulties 
in deep-water exploration and development. The difference between $\mathrm{EROI}_{D O G}$ and EROI $_{O N D O G}$ became negative and large with the influences of these multiple factors.

We have analyzed the reasons why $\mathrm{EROI}_{D O G}$ rose up again in recent years. However, one interesting thing should also be noticed: what drives the decline of $\mathrm{EROI}_{D O G}$ during 1998 and 2003. In other words, what constrain the DOG production promotion despite of the investment? We conclude there are two reasons for this phenomenon: 1) Limited growth in OG resources. The proven oil reserve barely increased in that period, and maintained about 15.6 billion barrels until 2010. Meanwhile, the proven gas reserve maintained about 1.4 trillion cubic meters until 2004. After 2004, the proven gas reserve increased fast. 2) OG development stage. A lot of oil fields are in the late development stage, the production declined despite of the heavy investment on enhanced oil recovery process.

\subsection{EROIs analysis of IOG}

EROI $_{I O G}$ was very volatile, which varied in the range between 2.9 to 9.5 . In general, EROI $_{I O G}$ showed a decline tendency. The $\mathrm{EROI}_{I O G}$ trend is determined by the ratio of imported natural gas volume relative to $\mathrm{OG}$ imported volume (namely the natural gas percentage), and the $\mathrm{EROI}_{N G}$ and $\mathrm{EROI}_{C O}$. During the 9th five-year plan period and 10th five-year plan period, China relied more on domestic natural gas. However, since China entered the 11th five-year plan period, China started to encourage the imports of natural gas. As shown in Fig. 13(c), the EROIs of imported natural gas $\left(\mathrm{EROI}_{I G}\right)$ is higher than the EROIs of imported crude oil $\left(\mathrm{EROI}_{I O}\right)$; the EROI ${ }_{I O G}$ started to increase from 2006 since China started to import natural gas, and the difference between $\mathrm{EROI}_{I O G}$ and $\mathrm{EROI}_{I O}$ became larger as the natural gas percentage became larger.

There are two reasons which contribute to the relatively high $\mathrm{EROI}_{I G}$ value: 1) The imported price of natural gas is relative lower than that of the crude oil. Meanwhile, the EROI of IOG is negatively correlated with the imported price (see Fig. 13(d)). 2) The 
natural gas is in the early development stage, low energy inputs can generate high energy outputs. Meanwhile, the crude oil is in the late development stage. Therefore, the EROI $I G$ is relative high.

There is a noteworthy value in the historical $\mathrm{EROI}_{I O G}$ : the $\mathrm{EROI}_{I O G}$ was about 2.9 in 2008. There are two reasons for this low value: 1) The imported unit price was relative high in 2008. As we can see in Fig. 13(d), the unit price was as high as 712 \$/MTOE. The high price enlarged the energy inputs. 2) The $\mathrm{E}_{\text {eint }}$ was relative high in 2008. Although the unit prices in 2011, 2012 and 2013 were slightly higher than that in 2008, the $\mathrm{E}_{\text {eint }}$ in 2008 was higher than those in 2011, 2012 and 2013 (see Fig. 6). Overall, the decreasing effects of the declined $\mathrm{E}_{\text {eint }}$ offset the increasing effects of the increased price. Therefore, the EROI $_{I O G}$ in 2008 is the lowest.

$<$ Figure 13 here >

\subsection{The comparison between EROIs of DOG and IOG}

By observing Fig. 11, we can conclude that: 1) EROIs of the entire DOG, offshore DOG, onshore DOG and IOG are higher than the EROI baseline, which implies that all of them are feasible from the perspective of physical input and output efficiency. 2) All $\mathrm{EROI}_{D O G}, \mathrm{EROI}_{O N D O G}$ and $\mathrm{EROI}_{O F D O G}$ are higher than $\mathrm{EROI}_{I O G}$, indicating that the DOG has a better energetic physical performance than IOG. But we cannot neglect the importance of IOG because the OG resources in China is limited.

\subsection{EROIs analysis of IOG from different countries}

EROI $_{I O G}$ depends on the imported prices. As we can see from Fig. 13(d), there is an obvious negative relationship between imported prices and $\mathrm{EROI}_{I O G}$. In order to undertake a more meticulous studies, the EROIs of different imported countries are calculated. The results from 2012 to 2015 are shown in Fig. 14 (more results are show in Table A7-A8). 
From Fig. 14, we can conclude that: 1) Overall, EROI ER $_{I}$ is higher than $\mathrm{EROI}_{I O}$. To be specific, $\mathrm{EROI}_{I G}$ of pipeline gas $\left(\mathrm{EROI}_{P G}\right)$ is the highest in 2015, $\mathrm{EROI}_{I G}$ of LNG $\left(\mathrm{EROI}_{L N G}\right)$ ranked the second, and the $\mathrm{EROI}_{I O}$ is the smallest. 2) The unit imported price has a negative relationship with EROI. As we can see from Fig. 14, the higher the imported price is, the lower the EROI is. 3) Combined with data in Table A7 and A8, we conclude that from the perspective of China, Australia LNG had the highest EROI $_{L N G}$ in all LNG exporters, Kazakhstan pipeline gas had the highest $\mathrm{EROI}_{P G}$ in all pipeline exporters, and the USA crude oil had the highest $\mathrm{EROI}_{I O}$ in the past five years. Besides the average EROIs of the long-cooperation exporters (who export OG to China since 1997) were similar, and were about 5. The average EROIs of crude oil from Venezuela, Columbia and Mexico reached to 6, while the average EROIs of crude oil from Thailand and Algeria were just about 4.

The bubble size in Fig. 14 reflects the imported volume. It is obvious that a large percent of IOG resources are imported from countries with low EROI ${ }_{I O G}$. Therefore, China should cogitate how to enhance the $\mathrm{EROI}_{I O G}$ by optimizing the import structure. Australia, Kazakhstan, and the USA should be prioritized in the optimization process.

$<$ Figure 14 here >

\section{Conclusions and policy recommendations}

By applying EROI to analyze the DOG, offshore DOG, onshore DOG, and IOG, we conclude that: 1) Overall, the EROIs of DOG were higher than those of IOG. 2) The EROIs of DOG and onshore DOG fluctuated in the range between 8.5 and 12.0 and the range between 8.2 to 13.5 respectively. The EROIs of offshore DOG decreased to 7.2 in 2013 but increased to 8.5 in 2014. The EROIs of IOG were fluctuating. 3) The EROI change tendency was decided by EROIs of crude oil, EROIs of natural gas, and gas production percentage. 4) The EROIs of IOG had a clear negative relationship with imported price. 
The EROIs of LNG and pipeline gas was higher than those of crude oil; 5) From an EROI perspective, China should prioritize Australia, Kazakhstan, and the USA if optimizing the energy features of its import structure.

Based on the results, several suggestions are proposed here:

(1) Encouraging the development of DOG, especially the natural gas. The EROIs of DOG outnumbered the EROIs of IOG. Therefore, the government should take different methods to stimulate the investment in the DOG. There are two ways to promote the development of the DOG. On one hand, China should push its marketization reform on the price mechanism of oil and gas products and access mechanism of the upstream oil and gas industry. By apoting this method, the government can rely on the "invisible hand" of the market economy. More enterprises will participate in the DOG industry, which in return intensifies the competition and improve the efficiency. Besides, the governments can provide subsidies, investment compensation, and low-interest loan to attract private capitals to involve in DOG industry.

China should pay more attention to the development of natural gas because the EROIs of natural gas were relatively high. The development of natural gas in China is still in early stage. Therefore, the infrastructure of natural gas is inadequate, such as the pipeline, the storage tanks and so on. Besides, the application of natural gas is usually limited to chemical industry, and cooking and heating for residents. Therefore, to facilitate the development of natural gas, the government should make plans for the construction of natural gas infrastructure, and encourage the development of the distributed generation using natural gas, the use LNG or natural gas fuel, and the civil use.

(2) Optimizing the imported structure of IOG. Although the EROIs of IOG were low compared to that of DOG, China still needs to import plenty of oil and gas (especially the natural gas) to fill the gaps between demand and domestic supply. Besides, the potential of oil and gas in China is limited. Therefore, China should continue to import oil and gas. 
However, as the IOG from different countries generates different EROIs, China should optimize the imported structure. From an EROI perspective, China should prioritize Australia, Kazakhstan, and the USA if optimizing the energy features of its import structure. Moreover, the government could make use of the "one belt and one road" strategy when importing the oil and gas because the EROIs of oil and gas producers, which locate in the rang of "one belt and one road", are relatively high. Therefore, China can reinforce energy cooperation with these oil and gas producers. Meanwhile, China should promote the construction of oil and gas pipeline and LNG receiving stations in order to import more oil and gas.

(3) Developing environmental technologies. Air emissions receive more and more attention as people start to stress the sustainability of the world and economy, and they have negative impacts on EROIs. As both DOG and IOG generate air emission, environmental technologies should be applied in the process of both DOG and IOG, despite that the use of such technologies will increase the energy inputs and decrease the EROI. To be specific, the government can promote the application of the existing technologies, such as carbon capture and storage. Moreover, the government could develop sophisticated technologies which can lower the costs and energy consumption of the current technologies.

\section{Acknowledgments}

This work is supported by the Young Fund of Shanxi University of Finance and Economics (No. QN-2018002), National Natural Science Foundation of China (No. 71774105) and Shanxi Repatriate Study Abroad Foundation (No. 2016-3). 


\section{Appendix A}

$<$ Table A1-A9 here >

\section{References}

Arvesen, A., Hertwich, E.G., 2015. More caution is needed when using life cycle assessment to determine energy return on investment (EROI). Energy Policy 76, 1-6.

Atlason, R., Unnthorsson, R., 2014. Ideal EROI (energy return on investment) deepens the understanding of energy systems. Energy 67, 241-245.

Aucott, M., Hall, C., 2014. Does a change in price of fuel affect GDP growth? An examination of the U.S. data from 1950-2013. Energies 7, 6558-6570.

Beal, C.M., Hebner, R.E., Webber, M.E., Ruoff, R.S., Seibert, A.F., King, C.W., 2012. Comprehensive evaluation of algal biofuel production: Experimental and target results. Energies 5, 1943-1981.

BP. BP energy outlook 2035; BP p.l.c.: London, UK, 2015.

BP. BP statistical review of world energy 2016; BP p.l.c.: London, UK, 2016.

Brand-Correa, L., Brockway, P., Copeland, C., Foxon, T., Owen, A., Taylor, P., 2017. Developing an Input-Output Based Method to Estimate a National-Level Energy Return on Investment (EROI). Energies 10, 534.

Brandt, A.R., 2011. Oil depletion and the energy efficiency of oil production: The case of California. Sustainability 3, 1833-1854.

Brandt, A.R., Dale, M., 2011. A general mathematical framework for calculating systems-scale efficiency of energy extraction and conversion energy return on investment (EROI) and other energy return ratios. Energies 4, 1211-1245.

Brandt, A.R., Dale, M., Barnhart, C.J., 2013. Calculating systems-scale energy efficiency and net energy returns: A bottom-up matrix-based approach. Energy 62, 235-247.

Brandt, A.R., Englander, J., Bharadwaj, S., 2013. The energy efficiency of oil sands extraction: Energy return ratios from 1970 to 2010. Energy 55, 693-702.

Brandt, A.R., Yeskoo, T., Vafi, K., 2015. Net energy analysis of Bakken crude oil production using a well-level engineering-based model. Energy 93, 2191-2198.

Chen, Y., Feng, L., Wang, J., Höök, M., 2017. Emergy-based energy return on investment method for evaluating energy exploitation. Energy 128, 540-549.

Cleveland, C., 2005. Net energy from the extraction of oil and gas in the United States. Energy 30, 769-782.

Cleveland, C.J., Costanza, R., Hall, C.A.S., Kaufmann, R., 1984. Energy and the U.S. Economy: A Biophysical Perspective. Science 225, 890-897.

Cleveland, C.J., O Connor, P.A., 2011. Energy Return on Investment (EROI) of Oil Shale. Sustainability 3, 2307-2322. 
Court, V., Fizaine, F., 2017. Long-Term Estimates of the Energy-Return-on-Investment (EROI) of Coal, Oil, and Gas Global Productions. Ecological Economics 138, 145-159.

Dale, M., Krumdieck, S., Bodger, P., 2011a. A dynamic function for energy return on investment. Sustainability 3, 1972-1985.

Dale, M., Krumdieck, S., Bodger, P., 2011b. Net energy yield from production of conventional oil. Energy Policy 39, 7095-7102.

Dupont, E., Koppelaar, R., Jeanmart, H., 2018. Global available wind energy with physical and energy return on investment constraints. Applied Energy 209, 322-338.

Feng, J., Feng, L., Wang, J., 2018. Analysis of Point-of-Use Energy Return on Investment and Net Energy Yields from China's Conventional Fossil Fuels. Energies 11, 313.

Feng, J., Feng, L., Wang, J., King, C.W., 2018. Modeling the point of use EROI and its implications for economic growth in China. Energy 144, 232-242.

Font De Mora, E., Torres, C., Valero, A., 2012. Assessment of biodiesel energy sustainability using the exergy return on investment concept. Energy 45, 474-480.

Freise, J., 2011. The EROI of conventional Canadian natural gas production. Sustainability 3, 2080-2104.

Gagnon, N., Hall, C.A.S., Brinker, L., 2009. A Preliminary Investigation of Energy Return on Energy Investment for Global Oil and Gas Production. Energies 2, 490-503.

Gately, M., 2007. The EROI of U.S. offshore energy extraction: A net energy analysis of the Gulf of Mexico. Ecological Economics 63, 355-364.

Grandell, L., Hall, C.A.S., Höök, M., 2011. Energy return on investment for Norwegian oil and gas from 1991 to 2008. Sustainability 3, 2050-2070.

Guilford, M.C., Hall, C.A.S., O Connor, P., Cleveland, C.J., 2011. A New Long Term Assessment of Energy Return on Investment (EROI) for U.S. Oil and Gas Discovery and Production. Sustainability 3, 1866-1887.

Gupta, A.K., Hall, C.A.S., 2011. A Review of the Past and Current State of EROI Data. Sustainability 3, 1796-1809.

Hall, A.S.C., Balogh, S., Murphy, D.J.R., 2009. What is the minimum EROI that a sustainable society must have? Energies 2, 25-47.

Hall, C., Cleveland, C., Kaufmann, R., 1986. Energy and Resource Quality: The Ecology of the Economic Process. Wiley-InterScience, New York, NY, USA.

Hall, C., Lavine, M., Sloane, J., 1979. Efficiency of energy delivery systems: I. An economic and energy analysis. Environ. Manage. 3, 493-504.

Hall, C.A.S., 1972. Migration and Metabolism in a Temperate Stream Ecosystem. Ecology 53, 585-604

Hall, C.A.S., Cleveland, C.J., 1981. Petroleum Drilling and Production in the United States: Yield per Effort and Net Energy Analysis. Science 211, 576-579.

Hall, C.A.S., Lambert, J.G., Balogh, S.B., 2014. EROI of different fuels and the implications for society. Energy Policy 64, 141-152.

Henshaw, P.F., King, C., Zarnikau, J., 2011. System Energy Assessment (SEA), Defining a Standard Measure of EROI for Energy Businesses as Whole Systems. Sustainability 3, 1908-1943.

Heun, M.K., de Wit, M., 2012. Energy return on (energy) invested (EROI), oil prices, and energy transitions. Energy Policy 40, 147-158. 
Hu, Y., Feng, L., Hall, C.C.S., Tian, D., 2011. Analysis of the energy return on investment (EROI) of the huge Daqing oil field in China. Sustainability 3, 2323-2338.

Hu, Y., Hall, C.A.S., Wang, J., Feng, L., Poisson, A., 2013. Energy Return on Investment (EROI) of China's conventional fossil fuels: Historical and future trends. Energy 54, 352-364.

Huang, Y., Gan, X., Chiueh, P., 2017. Life cycle assessment and net energy analysis of offshore wind power systems. Renewable Energy 102, 98-106.

Kessides, I.N., Wade, D.C., 2011. Deriving an improved dynamic EROI to provide better information for energy planners. Sustainability 3, 2339-2357.

King, C.W., Hall, C.A.S., 2011. Relating Financial and Energy Return on Investment. Sustainability 3, 1810-1832.

Kittner, N., Gheewala, S.H., Kammen, D.M., 2016. Energy return on investment (EROI) of mini-hydro and solar PV systems designed for a mini-grid. Renewable Energy 99, 410-419.

Kong, Z., Dong, X., Liu, G., 2016. Coal-based synthetic natural gas vs. imported natural gas in China: a net energy perspective. J. Clean. Prod. 131, 690-701.

Kong, Z., Dong, X., Xu, B., Li, R., Yin, Q., Song, C., 2015. EROI Analysis for Direct Coal Liquefaction without and with CCS: The Case of the Shenhua DCL Project in China. Energies $8,786-807$.

Kunz, H., Hagens, N., Balogh, S., 2014. The influence of output variability from renewable electricity generation on net energy calculations. Energies 7, 150-172.

Lambert, J.G., Hall, C.A.S., Balogh, S., Gupta, A., Arnold, M., 2014. Energy, EROI and quality of life. Energy Policy 64, 153-167.

Leccisi, E., Raugei, M., Fthenakis, V., 2016. The energy and environmental performance of ground-mounted photovoltaic systems-A timely update. Energies 9, 622.

Li, X., Ou, X., Zhang, X., Zhang, Q., Zhang, X., 2013. Life-cycle fossil energy consumption and greenhouse gas emission intensity of dominant secondary energy pathways of China in 2010. Energy 50, 15-23.

LMT, 2015. Ship emissions calculator. Laboratory for Maritime Transport (LMT) of National Technical University of Athens.

Moerschbaecher, M., Day Jr., J.W., 2011. Ultra-Deepwater Gulf of Mexico Oil and Gas: Energy Return on Financial Investment and a Preliminary Assessment of Energy Return on Energy Investment. Sustainability 3, 2009-2026.

Murphy, D., Carbajales-Dale, M., Moeller, D., 2016. Comparing Apples to Apples: Why the Net Energy Analysis Community Needs to Adopt the Life-Cycle Analysis Framework. Energies 9, 917.

Murphy, D.J., Hall, C.A.S., 2011. Energy return on investment, peak oil, and the end of economic growth. Ann. NY. Acad. Sci. 1219, 52-72.

Murphy, D.J., Hall, C.A.S., Dale, M., Cleveland, C., 2011. Order from chaos: A preliminary protocol for determining the EROI of fuels. Sustainability 3, 1888-1907.

Neumeyer, C., Goldston, R., 2016. Dynamic EROI Assessment of the IPCC 21st Century Electricity Production Scenario. Sustainability 8, 421.

Nogovitsyn, R., Sokolov, A., 2014. Preliminary calculation of the EROI for the production of gas in Russia. Sustainability 6, 6751-6765.

Pa, A., Bi, X.T., Sokhansanj, S., 2013. Evaluation of wood pellet application for residential heating 
in British Columbia based on a streamlined life cycle analysis. Biomass and Bioenergy 49, 109-122.

Palcher, S., Herweyer, M.C., Hall, C.A.S., 2008. Appendix B: Crude and refined oil imported to the United States.

Pechsiri, J.S., Thomas, J.E., Risén, E., Ribeiro, M.S., Malmström, M.E., Nylund, G.M., Jansson, A., Welander, U., Pavia, H., Gröndahl, F., 2016. Energy performance and greenhouse gas emissions of kelp cultivation for biogas and fertilizer recovery in Sweden. Sci. Total. Environ. 573, 347-355.

Poisson, A., Hall, C., 2013. Time series EROI for Canadian oil and gas. Energies 6, 5940-5959.

Raugei, M., Fullana-i-Palmer, P., Fthenakis, V., 2012. The energy return on energy investment (EROI) of photovoltaics: Methodology and comparisons with fossil fuel life cycles. Energy Policy 45, 576-582.

Raugei, M., Leccisi, E., 2016. A comprehensive assessment of the energy performance of the full range of electricity generation technologies deployed in the United Kingdom. Energy Policy 90, 46-59.

Safronov, A., Sokolov, A., 2014. Preliminary Calculation of the EROI for the Production of Crude Oil and Light Oil Products in Russia. Sustainability 6, 5801-5819.

Sell, B., Murphy, D., Hall, C.A.S., 2011. Energy Return on Energy Invested for Tight Gas Wells in the Appalachian Basin, United States of America. Sustainability 3, 1986-2008.

Skone, T.J., Littlefield, J., Marriott, J., Cooney, G., Jamieson, M., Hakian, J., Schivley, G., 2014. Life Cycle Analysis of Natural Gas Extraction and Power Generation. National Energy Technology Laboratory.

Swenson, R., 2016. The solarevolution: Much more with way less, right now-The disruptive shift to renewables. Energies 9, 676.

Trivedi, P., Olcay, H., Staples, M.D., Withers, M.R., Malina, R., Barrett, S.R.H., 2015. Energy return on investment for alternative jet fuels. Applied Energy 141, 167-174.

Wang, J., Liu, M., McLellan, B.C., Tang, X., Feng, L., 2017. Environmental impacts of shale gas development in China: A hybrid life cycle analysis. Resources, Conservation and Recycling $120,38-45$.

Wang, K., Vredenburg, H., Wang, J., Xiong, Y., Feng, L., 2017. Energy Return on Investment of Canadian Oil Sands Extraction from 2009 to 2015. Energies 10, 614.

Weißbach, D., Ruprecht, G., Huke, A., Czerski, K., Gottlieb, S., Hussein, A., 2013. Energy intensities, EROIs (energy returned on invested), and energy payback times of electricity generating power plants. Energy 52, 210-221.

Xu, B., Feng, L., Wei, W., Hu, Y., Wang, J., 2014. A Preliminary Forecast of the Production Status of China's Daqing Oil field from the Perspective of EROI. Sustainability 6, 8262-8282.

Yaritani, H., Matsushima, J., 2014. Analysis of the energy balance of shale gas development. Energies 7, 2207-2227.

Zhang, Y., Colosi, L.M., 2013. Practical ambiguities during calculation of energy ratios and their impacts on life cycle assessment calculations. Energy Policy 57, 630-633. 


\title{
Domestic oil and gas or imported oil and gas - An energy return on investment perspective
}

Cheng Cheng ${ }^{a}$, Zhen Wang ${ }^{b, *}$, Jianliang Wang ${ }^{c}$, Mingming Liu ${ }^{b}$, Xiaohang Ren ${ }^{\mathrm{d}}$

\author{
${ }^{a}$ School of Management Science and Engineering, Shanxi University of Finance and Economics, 696 \\ Wucheng Road, Taiyuan City, Shanxi Province, 030006 China \\ ${ }^{\mathrm{b}}$ Academy of Chinese Energy Strategy, China University of Petroleum-Beijing, 18 Fuxue Road, \\ Changping, Beijing, 102249, China \\ ${ }^{\mathrm{c}}$ School of Business Administration, China University of Petroleum-Beijing, 18 Fuxue Road, \\ Changping, Beijing, 102249, China \\ ${ }^{\mathrm{d}}$ School of Mathematical Sciences, University of Southampton, Southampton SO17 1BJ, UK
}

\begin{abstract}
Both domestic oil and gas and imported oil and gas are essential to meet the enormous energy demand in China, which is incurred by its rapid economic growth. However, which is better than another? To address this issue, an energy return on investment (EROI) analysis, which is a useful method to evaluate the physical performance of an energy process, is applied. Besides, the EROIs time series of offshore domestic oil and gas and onshore domestic oil and gas are calculated, and the causes of the change tendency of EROIs time series are studied. The EROIs of imported oil and gas from different import countries are also calculated, laying the foundation for optimization of the import structure from an EROI perspective. Moreover, environmental inputs, which cause the externality of an energy process, are also studied. The results show that the EROIs of the entire domestic oil and gas fluctuate between 8.5 and 12, and the EROIs of the imported oil and gas lie in the range
\end{abstract}


between 2.9 and 9.5. We conclude that: 1) The EROIs of domestic oil and gas is higher than those of imported oil and gas, indicating that domestic oil and gas has a higher physical efficiency than imported oil and gas. 2) The change tendency of EROIs is influenced by the extractions of natural gas. Moreover, the EROIs of imported oil and gas are additionally related to oil and gas prices. 3) From an EROI perspective, LNG and pipeline gas are better than imported crude oil. Australia, Kazakhstan, and the USA should be prioritized for China to import LNG, pipeline gas, and crude oil respectively. 4) Environmental inputs reduce the EROIs. Therefore more caution should be paid on the reduction of environmental inputs.

Keywords: Energy return on investment; Domestic oil and gas; Imported oil and gas; Optimization of import structure; environmental inputs

\section{Introduction}

Oil and gas (OG) play a pivotal role in the modern industry, and OG demand is closely related to economic development. China has seen rapid growth in the economy since the reform and openness. Meanwhile, the demand for OG in China has increased significantly due to the rapid economic growth (see Fig. 1). To satisfy the substantial growth, China has begun to push the development of its domestic OG industry and to import OG from other producers. However, the gap between domestic production and consumption will become larger in the future. BP estimates that the imported OG volume will double its size and reach 836 million tons oil equivalent (MTOE) in 2035 (BP, 2015), indicating that the average annual growth rate is approximate $5.5 \%$.

\section{$<$ Figure 1 Here >}

There are two ways to bridge the gap, namely domestic OG (DOG) and imported OG (IOG). The DOG is always a vital supply source for China. Although China does not belong to oil-rich countries, there are still some potentials - the proven OG reserves in 
China were 2.5 billion tons and 3.8 trillion cubic meters respectively in 2015 (BP, 2016).

IOG serves as another important supply source for China and accounts for a significant proportion in the supply mix. Domestic productions and key suppliers of IOG for China in 2014 are shown in Fig. 2.

$<$ Figure 2 here >

\begin{tabular}{|c|c|c|c|}
\hline Abbreviations & & & \\
\hline $\mathrm{A}_{I G}$ & $\begin{array}{l}\text { Aggregate volume of imported } \\
\text { gas }\end{array}$ & $\mathrm{ENV}_{O F D O G}$ & $\begin{array}{l}\text { Environmental inputs of offshore } \\
\text { DOG }\end{array}$ \\
\hline $\mathrm{A}_{I O}$ & Aggregate volume of imported oil & $E N V_{O N D O G}$ & $\begin{array}{l}\text { Environmental inputs of onshore } \\
\text { DOG }\end{array}$ \\
\hline $\mathrm{CNOOC}$ & $\begin{array}{l}\text { China National Offshore Oil } \\
\text { Corporation }\end{array}$ & EROI & Energy return on investment \\
\hline CNPC & $\begin{array}{l}\text { China National Petroleum } \\
\text { Corporation }\end{array}$ & $\mathrm{EROI}_{C O}$ & EROI of crude oil \\
\hline DDA & $\begin{array}{l}\text { Dismantlement and site } \\
\text { restoration allowance }\end{array}$ & $\mathrm{EROI}_{D O G}$ & EROI of the entire DOG \\
\hline $\mathrm{DEF}_{i}$ & $\begin{array}{l}\text { DOG emission factor of emission } \\
i\end{array}$ & $\mathrm{EROI}_{D O G, e n v}$ & $\begin{array}{l}\text { EROI with environmental inputs of } \\
\text { the entire DOG }\end{array}$ \\
\hline DOG & Domestic oil and gas & $\mathrm{EROI}_{I O}$ & EROI of imported oil \\
\hline $\mathrm{E}_{D O G}$ & Entire DOG energy outputs & $\mathrm{EROI}_{I G}$ & EROI of imported gas \\
\hline $\mathrm{E}_{O F D O G}$ & Offshore DOG energy outputs & $\mathrm{EROI}_{I O G}$ & EROI of IOG \\
\hline $\mathrm{E}_{O N D O G}$ & Onshore DOG energy outputs & $\mathrm{EROI}_{I O G, e n v}$ & $\begin{array}{l}\text { EROI with environmental inputs of } \\
\text { IOG }\end{array}$ \\
\hline $\mathrm{E}_{P(I G)}$ & Unit price of the imported gas & $\mathrm{EROI}_{L N G}$ & EROI of LNG \\
\hline $\mathrm{E}_{P(I O)}$ & Unit price of the imported oil & $\mathrm{EROI}_{N G}$ & EROI of natural gas \\
\hline $\mathrm{E}_{P(o i l)}$ & Price per barrel of oil & $\mathrm{EROI}_{O F D O G}$ & EROI of offshore DOG \\
\hline $\mathrm{E}_{U(I G)}$ & $\begin{array}{l}\text { Unit energy output of the } \\
\text { imported gas }\end{array}$ & EROI $_{O F D O G, e n v}$ & $\begin{array}{l}\text { EROI with environmental inputs of } \\
\text { offshore DOG }\end{array}$ \\
\hline $\mathrm{E}_{U(I O)}$ & $\begin{array}{l}\text { Unit energy output of the } \\
\text { imported oil }\end{array}$ & $\mathrm{EROI}_{O N D O G}$ & EROI of onshore DOG \\
\hline $\mathrm{E}_{U(\text { oil })}$ & Unit energy content of oil & $\mathrm{EROI}_{O N D O G, e n v}$ & $\begin{array}{l}\text { EROI with environmental inputs of } \\
\text { onshore DOG }\end{array}$ \\
\hline $\mathrm{E}_{T}$ & Total energy & $\mathrm{EROI}_{P G}$ & EROI of pipeline gas \\
\hline $\mathrm{E}_{d}$ & Direct inputs of the entire DOG & $\mathrm{EROI}_{\text {stnd }}$ & Standard EROI \\
\hline $\mathrm{E}_{\text {eint }}$ & $\begin{array}{l}\text { Energy intensity of the entire } \\
\text { economy }\end{array}$ & $\mathrm{EROI}_{1, e n v}$ & $\begin{array}{l}\text { Standard EROI with environmental } \\
\text { inputs }\end{array}$ \\
\hline $\mathrm{E}_{i d}$ & Indirect inputs of the entire DOG & GDP & Gross domestic production \\
\hline $\mathrm{E}_{\text {iint }}$ & $\begin{array}{l}\text { Energy intensity of industrial } \\
\text { sector }\end{array}$ & IOG & Imported oil and gas \\
\hline $\mathrm{E}_{o}$ & DOG energy outputs & LNG & Liquefied natural gas \\
\hline $\mathrm{ECF}_{i}$ & External cost factor of emission $i$ & $\mathrm{M}_{i d}$ & $\begin{array}{l}\text { Monetary indirect costs of the entire } \\
\text { DOG }\end{array}$ \\
\hline $\mathrm{EE}$ & Exploration expenses & $\mathrm{M}_{O F D O G}$ & Monetary inputs of offshore DOG \\
\hline $\mathrm{EF}_{i}$ & $\begin{array}{l}\text { Emission factor of emission } i \\
\text { related to IOG }\end{array}$ & $\mathrm{OE}$ & Operating expenses \\
\hline EJ & Exajoule & OG & Oil and gas \\
\hline $\mathrm{ENV}_{D O G}$ & $\begin{array}{l}\text { Environmental inputs of the entire } \\
\text { DOG }\end{array}$ & $\mathrm{PJ}$ & Petajoule \\
\hline $\mathrm{ENV}_{I O G}$ & IOG environmental inputs & SINOPEC & $\begin{array}{l}\text { China Petroleum \& Chemical } \\
\text { Corporation }\end{array}$ \\
\hline
\end{tabular}


China needs more OG to support its economic development, and care more about the energy surplus and physical efficiency of OG supply. Therefore, several interesting questions arise: from a physical efficiency perspective, which way to obtain the OG resources is better for China, DOG or IOG? How do the physical efficiencies of different energy supply processes (namely the entire DOG, the onshore DOG, the offshore DOG, and IOG) change over time, and what causes the change tendency? Which oil-exporting countries are excellent choices for China? Besides, as environmental issues receive great attention globally, and more energy inputs are required to eliminate the pollutions, environmental issues can be regarded as energy inputs of an energy supply process and have considerable impacts on EROI. Thus, another question is proposed: What will happen to EROIs when environmental inputs are considered?

An energy return on investment (EROI) analysis is proposed to address such questions from the perspective of net energy analysis. EROI is the ratio of the aggregate produced energy to the aggregate consumed energy in an energy supply process (Hall et al., 1979). It is different from economic indicators because it measures the energetic physical performance. Therefore, it is a useful and straightforward indicator which reflects the net energy surplus to the society (Gupta and Hall, 2011; Murphy et al., 2011). The concept originated from ecology (Hall, 1972), and was first formally proposed by Hall et al. (1979). Later on, several important papers were published in Science and other journals by Hall, Cleveland, Kaufmann and others (Cleveland et al., 1984; Hall et al., 1986; Hall and Cleveland, 1981). Few studies were carried out after that. However, studies on EROI have sprung up again after 2005.

Two basic methodologies are applied in the EROI analysis, i.e. the bottom-up and the top-down. The choice of the methodologies is determined by the system boundaries and data restriction (Murphy et al., 2011). For bottom-up methodology, process analysis is a typical and standardized method - it divides an energy supply process into several 
procedures and estimates the EROI by summing up the inputs and outputs of each procedure. Life cycle assessment (LCA) belongs to process analysis, (Murphy et al., 2016) suggest that all researchers should apply LCA when calculating EROI, which makes the comparison between different energy technologies consistent. However, LCA is limited by data availability. As for top-down methodology, the economic input-output analysis is a typical method, in which inputs and outputs are derived from economic data. The dynamic function is another example of top-down methodology (Dale et al., 2011a). Recently, a hybrid methodology combining process analysis and economic input-output analysis is proposed recently to overcome data restriction (Murphy et al., 2011).

The mainstream protocol in EROI analysis is proposed by Murphy et al. (2011). Before that, studies on EROI were divergent because there was no consensus about the system boundaries. A two-dimensional framework was presented by Murphy et al. (2011) to confine the system boundaries. Apart from this protocol, several other protocols were proposed (Arvesen and Hertwich, 2015; Atlason and Unnthorsson, 2014; Brandt et al., 2013; Brandt and Dale, 2011; Chen et al., 2017; Dale et al., 2011a; Feng et al., 2018; Hall et al., 2009; Henshaw et al., 2011; Kessides and Wade, 2011; Zhang and Colosi, 2013). Most of these protocols are similar to Murphy's or are based on Murphy's, despite the frameworks proposed by Dale et al. (2011a) and Henshaw et al. (2011). However, these two frameworks focus on the physical principles, which leads to the neglect of economic properties of the energy carriers.

EROI analysis is applied in three areas: 1) To measure the performance of different energy systems, which is the most common application. Energetic physical performance of different energy supply processes are evaluated by EROIs analysis, including oil and gas (Brandt, 2011; Brandt et al., 2015; Cleveland, 2005; Court and Fizaine, 2017; Dale et al., 2011b; Feng et al., 2018; Freise, 2011; Gagnon et al., 2009; Gately, 2007; Grandell et al., 2011; Guilford et al., 2011; Hall et al., 2014; Hu et al., 2011; Hu et al., 2013; Kong et al., 
2016; Moerschbaecher and Day Jr., 2011; Nogovitsyn and Sokolov, 2014; Poisson and Hall, 2013; Safronov and Sokolov, 2014; Xu et al., 2014), coal (Court and Fizaine, 2017; Feng et al., 2018; Hall et al., 2014; Hu et al., 2013), shale oil and gas (Cleveland and O Connor, 2011; Sell et al., 2011; Wang et al., 2017; Yaritani and Matsushima, 2014), oil sand (Brandt et al., 2013; Wang et al., 2017), power generation (including wind and solar power generation) (Dupont et al., 2018; Huang et al., 2017; Kittner et al., 2016; Kunz et al., 2014; Leccisi et al., 2016; Neumeyer and Goldston, 2016; Raugei et al., 2012; Raugei and Leccisi, 2016; Swenson, 2016; Weißbach et al., 2013), coal to liquid and gas (Kong et al., 2015; Kong et al., 2016), jet fuel (Trivedi et al., 2015), energy production sector (Brand-Correa et al., 2017; Feng et al., 2018), and biofuel (Beal et al., 2012; Font De Mora et al., 2012; Pechsiri et al., 2016). 2) To compare the impacts of technology and depletion. Technology will enhance the EROI by promoting the efficiency. However, depletion will decrease the EROI. Their impacts are examined by several scholars (Brandt, 2011; Brandt et al., 2013; Cleveland, 2005; Gagnon et al., 2009; Gately, 2007; Grandell et al., 2011; Guilford et al., 2011; Hall et al., 2014; Hu et al., 2011; Nogovitsyn and Sokolov, 2014; Poisson and Hall, 2013; Safronov and Sokolov, 2014; Sell et al., 2011). 3) To study the relationship between economy and EROI. Recently, the relationship between oil price, economic performance, and EROI receives more attention (Aucott and Hall, 2014; Heun and de Wit, 2012; King and Hall, 2011; Murphy and Hall, 2011).

Although previous studies have expanded the application fields of EROI analysis, little attention is paid to the comparison of EROIs of DOG process and IOG process in China, let alone the comparison of EROIs of offshore DOG and EROIs of onshore DOG and the causal analysis of the change tendency of different EROIs time series. Besides, the externalities (pollutions), which are generated during the OG production or trade processes and influence the energetic performance, are often neglected in the EROI analysis. Hu et al. (2013) calculated the EROIs of fossil fuels in China, but they overlooked the difference 
between the EROIs of onshore DOG and offshore DOG and the impacts of pollutions. To bridge the research gaps and to address the practical problems, we conduct EROI analyses compare the performance of DOG and IOG in China; to analyze the historical performance of DOG, offshore DOG, onshore DOG, and IOG; and to compare the performance of different IOG. Besides, the EROIs with environmental inputs are calculated to study the impacts of pollutions. This study has twofold meanings: 1) this study fill the gaps and extends the application areas of EROI analysis, and take environmental issues into consideration, which modifies standard EROI. 2) this study provide the policymakers with suggestions about the development of OG in China from an EROI perspective.

The layout of the rest of this paper is as follows. Section 2 discusses the methodology of DOG and IOG. Section 3 describes the calculation process of energy inputs and outputs of DOG. Section 4 describes the calculation process of energy inputs and outputs of IOG. In section 5, different EROIs are obtained, and the critical issues are discussed in this section. Section 6 provides the concluding remarks and policy recommendations.

\section{Methodology}

\subsection{Standard EROI and EROI with environmental inputs}

EROI is the ratio between the aggregate energy outputs and energy inputs of an energy process, to be specific, EROI is calculated by Equation (1):

$$
\text { EROI }=\frac{\text { Energy outputs }}{\text { Energy inputs }}
$$

Equation (1) is the basic concept of EROI.

EROI of an energy process is expressed by $\mathrm{x}$ : 1 , which indicates that $\mathrm{x}$ units energy are produced at the cost of 1 unit energy. Both the numerator and denominator are in energy units. Thus, EROI is a unitless indicator. Therefore, it is widely used to measure and compare the physical performance of different energy processes because of its convenience 
and straightforwardness. The baseline of EROI is 1, which indicates that the energy outputs are only enough to cover the energy inputs.

Identification of system boundaries is noteworthy, and two questions are closely related to the identification of system boundaries, namely, "what should be counted as inputs?" and "what should be counted as outputs?" (Murphy et al., 2011). To address these two questions, we apply the two-dimensional framework proposed by Murphy et al. (2011). Besides, we set the Chinese borderline as the physical boundaries in order to compare the EROIs of DOG and IOG. To be specific, regarding the DOG, we only consider the energy inputs and outputs in the extraction process, which is in line with the standard EROI $\left(\mathrm{EROI}_{\text {stnd }}\right)$ in Murphy's framework. As for IOG, we only consider the energy inputs and outputs related to exported goods and service production and international transportation from the $\mathrm{OG}$ exporters to China, and neglect the energies relative to domestic transportation and international transportation from China to importers. Pollution belongs to an external input of an energy process. To study the impacts of pollutions, standard EROI with environmental inputs $\left(\mathrm{EROI}_{1, e n v}\right)$ is estimated and serves as a sensitivity analysis.

\subsection{EROI of DOG}

\subsubsection{EROI estimation for the entire DOG}

The entire DOG EROI is meant to evaluate the energetic physical performance of entire DOG extraction industry. The system boundary is shown in Fig. 3. With reference to Murphy et al. (2011), energy outputs are determined by the extracted unprocessed OG, and energy inputs are divided into direct and indirect inputs. Due to the data restriction, we apply a hybrid methodology (process analysis and economic input-output analysis) to calculate the EROI (see other examples in Hu et al., 2013; Poisson and Hall, 2013): Direct inputs measure the physical energy inputs, including crude oil, gasoline, kerosene, diesel, fuel, liquefied petroleum gas, refinery gas, other petroleum products, natural gas, liquefied 
natural gas (LNG), heat, electricity, other energy and raw coal. Indirect inputs are the embodied energy of material inputs which are constructed offsite, such as equipment and instrument. Environmental inputs measure the energy inputs of greenhouse emissions, such as $\mathrm{CO}_{2}, \mathrm{CH}_{4}$, and $\mathrm{NO}_{\mathrm{X}}$.

\section{$<$ Figure 3 here >}

The EROIs of the entire DOG without environmental inputs $\left(\mathrm{EROI}_{D O G}\right)$ and the EROIs of the entire DOG with environmental inputs $\left(\mathrm{EROI}_{D O G, \text { env }}\right)$ are calculated by the following equations:

$$
\begin{gathered}
\mathrm{EROI}_{D O G}=\frac{\mathrm{E}_{D O G}}{\mathrm{E}_{d}+\mathrm{E}_{i d}}=\frac{\mathrm{E}_{D O G}}{\mathrm{E}_{d}+\mathrm{M}_{i d} \times \mathrm{E}_{i i n t}} \\
\mathrm{EROI}_{D O G, e n v}=\frac{\mathrm{E}_{D O G}}{\mathrm{E}_{d}+\mathrm{M}_{i d} \times \mathrm{E}_{i i n t}+\mathrm{ENV}_{D O G}}
\end{gathered}
$$

where $\mathrm{E}_{D O G}$ denotes the energy outputs of the entire DOG, $\mathrm{E}_{d}$ denotes the direct inputs of the entire DOG, $\mathrm{E}_{i d}$ denotes the indirect inputs of the entire DOG, $\mathrm{M}_{i d}$ denotes the monetary indirect costs of the entire DOG, $\mathrm{E}_{\text {iint }}$ denotes the energy intensity of the industrial sector, and $\mathrm{ENV}_{D O G}$ denotes the environmental inputs of the entire DOG. Equation (2) and (3) are used to calculate the standard EROI and the EROI with environmental inputs of the entire DOG.

\subsubsection{EROI estimation for the offshore DOG}

The offshore DOG EROI is meant to evaluate the physical efficiency of offshore OG extraction industry. The system boundary is shown in Fig. 4. The extracted OG is the outputs. As available inputs data is in monetary units, we apply the economic input-output method to calculate the energy inputs, see another example in Gagnon et al. (2009). We apply $\mathrm{E}_{\text {iint }}$ to convert the monetary inputs into energy units. Another challenge is the monetary inputs are not available for China National Petroleum Corporation (CNPC) and China Petroleum \& Chemical Corporation (SINOPEC). Considering that most offshore 
DOG are produced by China National Offshore Oil Corporation (CNOOC) and the CNOOC monetary inputs is the only available data, we assume that the unit offshore monetary input is same for CNOOC, CNPC, and SINOPEC. Then, we estimate the offshore DOG EROI based on CNOOC data.

$<$ Figure 4 here $>$

The EROIs of the offshore DOG without environmental inputs $\left(\mathrm{EROI}_{\text {OFDOG }}\right)$ and the EROIs of the offshore DOG with environmental inputs $\left(\mathrm{EROI}_{O F D O G, e n v}\right)$ are calculated by the follows equations:

$$
\begin{gathered}
\mathrm{EROI}_{O F D O G}=\frac{\mathrm{E}_{O F D O G}}{\mathrm{M}_{O F D O G} \times \mathrm{E}_{i i n t}} \\
\mathrm{EROI}_{O F D O G, \text { env }}=\frac{\mathrm{E}_{\text {OFDOG }}}{\mathrm{M}_{O F D O G} \times \mathrm{E}_{\text {iint }}+\mathrm{ENV}_{O F D O G}}
\end{gathered}
$$

where $\mathrm{E}_{\text {OFDOG }}$ denotes the energy outputs of offshore DOG, $\mathrm{M}_{\text {OFDOG }}$ denotes the monetary inputs of offshore DOG, $\mathrm{E}_{\text {iint }}$ denotes the energy intensity of the industrial sector, and $\mathrm{ENV}_{\text {OFDOG }}$ denotes the environmental inputs of offshore DOG. Equation (4) and (5) are used to calculate the standard EROI and the EROI with environmental inputs of offshore DOG.

\subsubsection{EROI estimation for the onshore DOG}

Energy outputs of onshore DOG are calculated based on the annual production data. Energy inputs of onshore DOG are calculated as the difference between the entire DOG's energy inputs and the offshore DOG's. Therefore, the EROIs of the onshore DOG without environmental inputs $\left(\mathrm{EROI}_{O N D O G}\right)$ and the EROIs of the onshore DOG with environmental inputs $\left(\mathrm{EROI}_{O N D O G, \text { env }}\right)$ are calculated by the follows equations:

$$
\mathrm{EROI}_{O N D O G}=\frac{\mathrm{E}_{O N D O G}}{\mathrm{E}_{D O G}-\mathrm{E}_{O F D O G}}
$$




$$
\mathrm{EROI}_{O N D O G, e n v}=\frac{\mathrm{E}_{O N D O G}}{\mathrm{E}_{D O G}-\mathrm{E}_{O F D O G}+\mathrm{ENV}_{O N D O G}}
$$

where $\mathrm{E}_{O N D O G}$ denotes the energy outputs of onshore DOG, $\mathrm{E}_{D O G}$ denotes the energy outputs of the entire DOG, $\mathrm{E}_{\text {OFDOG }}$ denotes the energy inputs of offshore DOG, and $\mathrm{ENV}_{\text {ONDOG }}$ denotes the onshore DOG environmental inputs. Equation (6) and (7) are used to calculate the standard EROI and the EROI with environmental inputs of onshore DOG.

\subsection{EROI of IOG}

EROI of IOG measures the energetic physical performance of IOG process. To be specific, it is the ratio between the energy content of the purchased OG and the energy content of OG embodied in goods and services which are required to generate the necessary foreign exchange. The system boundary is shown in Fig. 5. Energy inputs, which are usually derived from economic data, include the embodied energies of the exported goods and services and the energies for international transportation from OG exporters to China. Energy outputs are the imported OG. The first explicit method to estimate the IOG EROI was proposed by Kaufmann (Hall et al., 1986), in which EROI for imported oil $\left(\mathrm{EROI}_{I O}\right)$ is calculated as:

$$
\mathrm{EROI}_{I O}=\frac{\mathrm{E}_{U(\text { oil })}}{\left(\mathrm{E}_{T} / \mathrm{GDP}\right) \times \mathrm{E}_{P(o i l)}}
$$

where $\mathrm{E}_{U(\text { oil })}$ is the unit energy content of oil, $\mathrm{E}_{T}$ is the total energy, GDP is the gross domestic production, and $\mathrm{E}_{P(\text { oil })}$ is the price per barrel of oil. Equation (8) is used to calculate the EROI of IO by Kaufmann.

$<$ Figure 5 here $>$

With reference to Equation (8), the EROI of IOG without environmental inputs $\left(\mathrm{EROI}_{I O G}\right)$ and the EROI of IOG with environmental inputs $\left(\mathrm{EROI}_{I O G, \text { env }}\right)$ are calculated as follows: 


$$
\begin{gathered}
\mathrm{EROI}_{I O G}=\frac{\mathrm{E}_{U(I O)} \times \mathrm{A}_{I O}+\mathrm{E}_{U(I G)} \times \mathrm{A}_{I G}}{\mathrm{E}_{\text {eint }} \times\left(\mathrm{E}_{P(I O)} \times \mathrm{A}_{I O}+\mathrm{E}_{P(I G)} \times \mathrm{A}_{I G}\right)} \\
\mathrm{EROI}_{I O G, e n v}=\frac{\mathrm{E}_{U(I O)} \times \mathrm{A}_{I O}+\mathrm{E}_{U(I G)} \times \mathrm{A}_{I G}}{\mathrm{E}_{\text {eint }} \times\left(\mathrm{E}_{P(I O)} \times \mathrm{A}_{I O}+\mathrm{E}_{P(I G)} \times \mathrm{A}_{I G}\right)+\mathrm{ENV}_{I O G}}
\end{gathered}
$$

where $\mathrm{E}_{U(I O)}$ denotes the unit energy output of the imported oil (IO), $\mathrm{A}_{I O}$ denotes the aggregate volume of $\mathrm{IO}, \mathrm{E}_{U(I G)}$ denotes the unit energy output of the imported gas (IG), $\mathrm{A}_{I G}$ denotes the aggregate volume of $\mathrm{IG}, \mathrm{E}_{P(I O)}$ denotes the unit price of the IO, $\mathrm{E}_{P(I G)}$ denotes the unit price of the IG, $\mathrm{E}_{\text {eint }}$ denotes the energy intensity of the entire economy, and $\mathrm{ENV}_{I O G}$ denotes the environmental inputs of IOG. Equation (9) and (10) are used to calculate the standard EROI and the EROI with environmental inputs of IOG.

\subsection{Energy conversion and environmental inputs}

\subsubsection{Energy conversion}

Two types of energy unit conversion are applied in this paper according to the data type: 1) Energy equivalent is employed for physical data; 2) Energy intensity is applied to monetary data. Energy equivalent measures the average calorific value of an energy carrier. It is used to convert the physical units into energy units. The energy equivalent of common energies is listed in Table 1.

\section{$<$ Table 1 here >}

Energy intensity, which measures the energy consumptions (in energy units) per gross domestic product or value-added by sectors (in monetary units), is applied to convert monetary units into energy units. Data on the annual industrial added value of OG extraction industry is not intact, especially the data before 2006, so it is hard to calculate the energy intensity of OG extraction industry. Therefore, the $\mathrm{E}_{i i n t}$ is alternatively applied as OG extraction is a subcategory of the industrial sector, see other examples in Cleveland (2005), Hu et al. (2011) and $\mathrm{Hu}$ et al. (2013). However, the $\mathrm{E}_{\text {eint }}$ is employed to calculate 
the EROI of IOG and the environmental inputs because the two processes involve products of the primary, secondary and tertiary industry. The energy intensity of both the industrial sector and the entire economy are shown in Fig. 6. The $\mathrm{E}_{\text {iint }}$ is higher than the $\mathrm{E}_{\text {eint }}$ for two reasons: 1) China's economy highly depends on the industry. The industrial added value accounted for about 40\% during 2000 and 2014. 2) The industrial sector is featured with high energy intensity because many energy-intensive industries belong to the industrial sector, such as smelting and pressing of ferrous metals, manufacture of raw chemical materials and chemical products, and manufacture of non-metallic mineral products.

\section{$<$ Figure 6 here >}

\subsubsection{Environmental inputs}

Two methods are applied to calculate the environmental inputs due to the available data. Regarding DOG, the environmental inputs are computed on the basis of energy outputs. Li et al.(2013) estimate the greenhouse emission of dominant secondary energy in China, we use their results to calculate the environmental inputs of DOG. To be specific,

$$
\mathrm{ENV}=\sum_{i} \mathrm{E}_{o} \times \mathrm{DEF}_{i} \times \mathrm{ECF}_{i} \times \mathrm{E}_{e i n t}
$$

where $\mathrm{E}_{o}$ is the energy outputs of DOG (in energy units), $\mathrm{DEF}_{i}$ is the DOG emission factor of emission $i$ (with $\mathrm{kg} / \mathrm{MJ}$ as the unit), $\mathrm{ECF}_{i}$ denotes the external cost factor of emission $i$ (with $\mathrm{kg} / \$$ as the unit), and $\mathrm{E}_{\text {eint }}$ denotes the energy intensity of the entire economy. Equation (11) is used to calculate the environmental inputs of DOG.

As for IOG, the environmental inputs are derived from monetary data. Energy intensity, emission factors, and external costs are employed to calculate the environmental inputs. To be specific, it is calculated by Equation (12). 


$$
\mathrm{ENV}=\sum_{i} \mathrm{EF}_{i} \times \mathrm{ECF}_{i} \times \mathrm{E}_{\text {eint }}
$$

where $\mathrm{EF}_{i}$ denotes the emission factor of emission $i$ in the exports production process and OG international transportation process (with $\mathrm{kg} / \$, \mathrm{~kg} / \mathrm{t} \cdot \mathrm{km}$, or $\mathrm{kg} / \mathrm{m}^{3} \cdot \mathrm{km}$ as units), $\mathrm{ECF}_{i}$ denotes the external cost factor of emission $i$ (with $\mathrm{kg} / \$$ as the unit), and $\mathrm{E}_{\text {eint }}$ denotes the energy intensity of the entire economy. Equation (12) is used to calculate the environmental inputs of IOG.

\subsection{Data}

There are three data sources in our paper, and they are noted in each table of this paper (apart from tables which contain the calculated results by using raw data): 1) Chinese official databases, such as China Energy Statistical Yearbook, China Statistical Yearbook, China Marine Statistical Yearbook, and General Administration of Customs. They are authoritative. These data start from 1997 to 2014, and include the production of crude oil and natural gas, consumption of different energies and so on. 2) Published statistical yearbook by international OG companies, such as BP. They are reliable. These data start from 1988 to 2015, and are used to describe the historical relationship among OG production, consumption, net import and so on. 3) Parameters from other published articles, such as $\mathrm{DEF}_{i}, \mathrm{EF}_{i}$, and $\mathrm{ECF}_{i}$. These papers are published after strict peer-review. They are also reliable. These data are fixed data, and are chosen from lasted papers (including papers from 2013 to 2016).

\section{Energy outputs, energy inputs and environmental inputs of DOG}

\subsection{Energy outputs, energy inputs and environmental inputs of the entire DOG}

\subsubsection{Energy outputs of the entire DOG}


The raw data of entire DOG energy outputs are collected in China Statistical Yearbook. We use the energy equivalents of crude oil and natural gas in Table 1 to convert the physical units to energy units, and the results are listed in Table 2.

$<$ Table 2 here >

\subsubsection{Energy inputs of the entire DOG}

For direct inputs, we collected data from China Energy Statistical Yearbook, which provides the physical consumption of different energies in OG extraction industry. The raw data are listed in Table A1. We use energy equivalent to converting the raw data to energy units. As for the indirect inputs, we collected data from China Statistic Yearbook. With reference to Hu et al. (2013), items of "purchase of equipment and instruments" and "others expenses" in fixed assets investment are counted as the indirect inputs in our analysis (see more details in Table A2). $\mathrm{E}_{\text {iint }}$ is applied to convert the monetary units to energy units. A sum of direct and indirect inputs are listed in Table 3.

$<$ Table 3 here >

\subsubsection{Environmental inputs of the entire DOG}

The entire DOG energy outputs are calculated in Section 3.1.1. The $\mathrm{DEF}_{i}$ is calculated by $\mathrm{Li}$ et al. (2013), and the $\mathrm{ECF}_{i}$ is obtained from Pa et al. (2013) (see details in Table A3). The annual exchange rate for each year from 1997 to 2014 is applied in the calculation, and it is obtained from China Statistical Yearbook. The entire DOG environmental inputs is then calculated by Equation (11) on the base of these parameters, and the results is shown in Fig. 7.

$<$ Figure 7 here >

3.2. Energy outputs, energy inputs and environmental inputs of the offshore DOG 
We apply the same method to calculate the offshore DOG energy outputs as we calculate the energy outputs of the entire DOG. Raw data of the output is collected from China Marine Statistical Yearbook. Energy equivalent is employed to convert the units, and the results are listed in Table 4.

$$
<\text { Table } 4 \text { here > }
$$

\subsubsection{Energy inputs of the offshore DOG}

As mentioned in Section 2.2.2, we estimate the offshore DOG energy inputs on the base of CNOOC data. Therefore, we collect the daily OG productions, operating expenses (OE), depreciation, depletion and amortization (including dismantlement and site restoration allowance, DDA), and exploration expenses (EE) from the CNOOC annual reports. OE, DDA, and EE are the annual monetary inputs for an oil company to extract OG resources, and they are converted to energy units by $E_{\text {iint }}$ (details are shown in Table A4). The CNOOC daily DOG productions are used to calculate the CNOOC production percentage in the whole offshore DOG (details are shown in Table A5). The offshore inputs is CNOOC inputs divided by production percentage (see Table 5).

$<$ Table 5 here >

\subsubsection{Environmental inputs of the offshore DOG}

We take the same procedure to calculate the environmental inputs of the offshore DOG as we calculate the environmental inputs of the entire DOG, and the result is shown in Fig. 8.

$<$ Figure 8 here >

\subsection{Energy outputs, energy inputs and environmental inputs of the onshore DOG}

\subsubsection{Energy outputs of the onshore DOG}


The onshore DOG raw data is obtained by subtracting the whole DOG production with offshore DOG production. Then, energy equivalent is used to convert the physical inputs to energy inputs. Results are shown in Table 6.

$<$ Table 6 here $>$

\subsubsection{Energy inputs of the onshore DOG}

The onshore DOG energy inputs are calculated by subtracting the entire DOG inputs with offshore DOG inputs, and the results are shown in Table 7.

$<$ Table 7 here >

\subsubsection{Environmental inputs of the onshore DOG}

We again apply the same approach to calculate the onshore DOG environmental inputs as we calculate the environmental inputs of the entire DOG, and it is shown in Fig. 9.

$<$ Figure 9 here >

\section{Energy outputs, energy inputs and environmental inputs of IOG}

\subsection{Energy outputs of IOG}

The IOG raw data is collected in China Statistical Yearbook and is converted to energy units by using the energy equivalent. The results are shown in Table 8.

$<$ Table 8 here >

\subsection{Energy inputs of IOG}

The IOG energy inputs are decided by the OG purchase costs, international transportation fees, exchange rate, and convention factor. The IOG monetary inputs are obtained from General Administration of Customs. The raw data is CIF price, which includes the international transportation fee. However, it is counted in US dollars. 
Therefore, the exchange rate is used in the calculation process. The results are shown in Table 9.

$<$ Table 9 here >

\subsection{Environmental inputs of $I O G$}

The IOG environmental inputs are calculated by Equation (12). The $\mathrm{EF}_{i}$ is obtained from Kong et al. (2016), LMT (2015), and Skone et al. (2014) (details are shown in Table A3). Another challenge arise when estimating the transportation distance. The transportation distances of crude oil tankers and LNG carriers are collected from a website which can estimate the distance between different ports. Pipeline distances are collected from Kong et al. (2016) (see details in Table A6). The average distance is used as the transportation distance. The IOG environmental inputs is shown in Fig. 10.

$<$ Figure 10 here >

\section{EROI results and discussions}

The EROIs of DOG, offshore DOG, onshore DOG, and IOG are shown in Fig. 11 (a). The EROIs which considers the environmental inputs are illustrated in Fig. 11 (b). Externalities are an interesting and valuable factor for EROI analysis for its economic value, rather than the energetic value (Murphy et al., 2011). It necessitates the extra monetary inputs to treat the pollutions or to purchase pollution control equipment or certified emission reductions. Therefore, it will decrease the EROI, which can be observed by comparing the Fig. 11 (a) and (b). Externalities' negative impacts on EROI is also observed in Kong et al. (2016).

< Figure 11 here >

Before we start to discuss the results, we compare our results with other scholars, which is shown in Fig. 12. We compare our results with the EROIs of global OG production (Gagnon et al., 2009) and the USA OG production (Cleveland, 2005), which 
can be seen in Fig. 12(a). The EROIs of China is lower than those of global and the USA. The development conditions in China is not good: lots of OG fields are located in mountains; the reservoir depth is also very large. Poor development conditions enlarge the energy inputs, leading to low EROIs. We also compare our results the EROIs of the USA imported crude oil (Palcher et al., 2008) and China imported crude oil (Lambert et al., 2014), which can be seen in Fig. 12(b). Our results are similar to that of Lambert's but are lower than that of the USA.

< Figure 12 here >

\subsection{EROIs analysis of DOG}

\subsubsection{EROIs analysis of the entire DOG}

$\mathrm{EROI}_{D O G}$ fluctuated in the range between 8.5 to 12.0 during this period. It rose a little in 1998, but kept decreasing until 2004, after that it started to grow in fluctuation. The trend of $\mathrm{EROI}_{D O G}$ is determined by the changes of natural gas production ratio, the natural gas EROI $\left(\mathrm{EROI}_{N G}\right)$, the crude oil EROI $\left(\mathrm{EROI}_{C O}\right)$, and the development changes of OG industry in China. In general, the EROIs of an energy process always tend to be high in the early stage, and then to decline along with the development. It is decided by both inputs and outputs of the process. Take crude oil as an example, the outputs of an oilfield always start to increase from 0 to peak production, keep for several years, and then decline. Meanwhile, the inputs are small in the early stage as oil are extracted by natural pressure, but start to increase in the mid and late stages because different measures, such as water injection, chemical flooding and gas flooding, are needed to enhance oil recovery. Moreover, the conventional oils have been developed for a long time and depleted a lot. Therefore, more and more unconventional oils are produced. Compared to that of conventional oil, the development of unconventional oil is much harder, and requires more sophisticated technology and monetary inputs, which decrease the EROI in return. 
Compared to the crude oil development, the natural gas development is still in the early stage, therefore, $\mathrm{EROI}_{N G}$ is in the growth stage, while EROI $\mathrm{E}_{C O}$ is in decline stage (Gupta and Hall, 2011). During the 9th five-year plan period (1996-2000) and 10th five-year plan period (2001-2005) in China, the Chinese government realized the importance of natural gas, and started to promote its development. For example, the Chinese government stated in the 9th and 10th five-year plan that China would increase the investment in exploration of both $\mathrm{OG}$, aiming to enhance the production of both OG. However, as the development of natural gas is still in the early stage, its production ratio is small compared to that of oil. In 1997, the ratio of natural gas production to the entire OG production was only about $11.3 \%$. The promotion effects of $\mathrm{EROI}_{N G}$ on the $\mathrm{EROI}_{D O G}$ was not strong enough to offset the reduction effects of $\mathrm{EROI}_{C O}$, therefore, $\mathrm{EROI}_{D O G}$ decreased during 1997 and 2004. During the 11th five-year plan period (2006-2010) and 12th five-year plan period (2011-2015), the Chinese government still promote the development of OG, especially the natural gas. Therefore, the natural gas production percentage kept increasing recently, and pushed the $\mathrm{EROI}_{D O G}$ to increase in fluctuation.

It is hard to decompose the DOG inputs into inputs of crude oil and natural gas because their inputs are mixed in the available data. Therefore, it is difficult to calculate the EROI $_{N G}$ and EROI $C O$. We alternatively studied the relationship between the energy inputs and EROIs. As we can see from Fig. 13(a), there is a negative correlation between growth rates of energy inputs and EROIs. We can infer that an increase in energy inputs could generally generate a decline in $\mathrm{EROI}_{D O G}$.

\subsubsection{EROIs analysis of offshore DOG and onshore DOG}

The trends of $\mathrm{EROI}_{O N D O G}$ and $\mathrm{EROI}_{O F D O G}$ are quite different. EROI $\mathrm{ENDOG}_{\text {ON }}$ fluctuated in the range between 8.2 and 13.5, and the its trend is similar to that of DOG because the onshore DOG is in a dominant position within the DOG supply mix. 
Meanwhile, EROI OFDOG $_{\text {ied }}$ in the range between 7.2 and 12.6. EROI OFDOG increased at first, then declined for several years, but rose a little in 2014. Overall, EROI $_{O F D O G}$ showed a decline tendency. This trend is caused by the development stage of offshore OG industry in China. The Chinese government always pay attention to the development of offshore OG. During the 9th five-year plan period, the Chinese government focused on the nearshore OG. Consequently, early exploration and development activities of offshore OG resources were conducted in the nearshore areas, whose costs were relative low. However, from the 10th five-year plan period, the Chinese government started to emphasize the development of deep-water resources, more and more deep-water resources were developed due to the promotion of offshore OG industry. The monetary inputs for deep-water fields are much larger than onshore and nearshore fields, which leads to the EROI $_{O F D O G}$ decline. The promotion of offshore OG industry is reflected by the increasing monetary inputs of offshore DOG. As we can see from Fig. 13(b), the monetary inputs is negatively correlated with $\mathrm{EROI}_{O F D O G}$, and has a growth tendency in recent years.

\subsubsection{The overall analysis of DOG}

Although the trends of $\mathrm{EROI}_{D O G}$ and $\mathrm{EROI}_{O N D O G}$ are similar, there is still a difference between them, especially before 2004 and after 2009. The difference is caused by the offshore OG production percentage and the EROI trends. To be specific, although

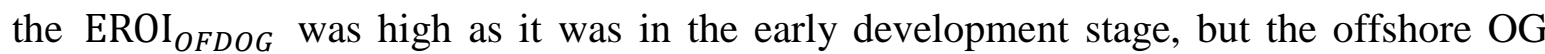
only accounted for about $14 \%$ before 2004 . On the other hand, the onshore DOG production overwhelmed the offshore DOG production despite of the low EROI ONDOG $_{\text {. }}$ These two features made the difference between $\mathrm{EROI}_{D O G}$ and $\mathrm{EROI}_{O F D O G}$ was positive and small. While after 2009, due to development guidance of offshore OG by the Chinese government, the production percentage of the offshore DOG became high, which reached to $18 \%$, but the $\mathrm{EROI}_{O F D O G}$ became smaller than $\mathrm{EROI}_{O N D O G}$ because of the difficulties 
in deep-water exploration and development. The difference between $\mathrm{EROI}_{D O G}$ and EROI $_{O N D O G}$ became negative and large with the influences of these multiple factors.

We have analyzed the reasons why $\mathrm{EROI}_{D O G}$ rose up again in recent years. However, one interesting thing should also be noticed: what drives the decline of $\mathrm{EROI}_{D O G}$ during 1998 and 2003. In other words, what constrain the DOG production promotion despite of the investment? We conclude there are two reasons for this phenomenon: 1) Limited growth in OG resources. The proven oil reserve barely increased in that period, and maintained about 15.6 billion barrels until 2010. Meanwhile, the proven gas reserve maintained about 1.4 trillion cubic meters until 2004. After 2004, the proven gas reserve increased fast. 2) OG development stage. A lot of oil fields are in the late development stage, the production declined despite of the heavy investment on enhanced oil recovery process.

\subsection{EROIs analysis of IOG}

EROI $_{I O G}$ was very volatile, which varied in the range between 2.9 to 9.5 . In general, EROI $_{I O G}$ showed a decline tendency. The $\mathrm{EROI}_{I O G}$ trend is determined by the ratio of imported natural gas volume relative to $\mathrm{OG}$ imported volume (namely the natural gas percentage), and the $\mathrm{EROI}_{N G}$ and $\mathrm{EROI}_{C O}$. During the 9th five-year plan period and 10th five-year plan period, China relied more on domestic natural gas. However, since China entered the 11th five-year plan period, China started to encourage the imports of natural gas. As shown in Fig. 13(c), the EROIs of imported natural gas $\left(\mathrm{EROI}_{I G}\right)$ is higher than the EROIs of imported crude oil $\left(\mathrm{EROI}_{I O}\right)$; the EROI ${ }_{I O G}$ started to increase from 2006 since China started to import natural gas, and the difference between $\mathrm{EROI}_{I O G}$ and $\mathrm{EROI}_{I O}$ became larger as the natural gas percentage became larger.

There are two reasons which contribute to the relatively high $\mathrm{EROI}_{I G}$ value: 1) The imported price of natural gas is relative lower than that of the crude oil. Meanwhile, the EROI of IOG is negatively correlated with the imported price (see Fig. 13(d)). 2) The 
natural gas is in the early development stage, low energy inputs can generate high energy outputs. Meanwhile, the crude oil is in the late development stage. Therefore, the EROI is relative high.

There is a noteworthy value in the historical $\mathrm{EROI}_{I O G}$ : the $\mathrm{EROI}_{I O G}$ was about 2.9 in 2008. There are two reasons for this low value: 1) The imported unit price was relative high in 2008. As we can see in Fig. 13(d), the unit price was as high as 712 \$/MTOE. The high price enlarged the energy inputs. 2) The $\mathrm{E}_{\text {eint }}$ was relative high in 2008. Although the unit prices in 2011, 2012 and 2013 were slightly higher than that in 2008, the $\mathrm{E}_{\text {eint }}$ in 2008 was higher than those in 2011, 2012 and 2013 (see Fig. 6). Overall, the decreasing effects of the declined $\mathrm{E}_{\text {eint }}$ offset the increasing effects of the increased price. Therefore, the in 2008 is the lowest.

$<$ Figure 13 here >

\subsection{The comparison between EROIs of DOG and IOG}

By observing Fig. 11, we can conclude that: 1) EROIs of the entire DOG, offshore DOG, onshore DOG and IOG are higher than the EROI baseline, which implies that all of them are feasible from the perspective of physical input and output efficiency. 2) All , $\mathrm{EROI}_{O N D O G}$ and $\mathrm{EROI}_{O F D O G}$ are higher than $\mathrm{EROI}_{I O G}$, indicating that the DOG has a better energetic physical performance than IOG. But we cannot neglect the importance of IOG because the OG resources in China is limited.

\subsection{EROIs analysis of IOG from different countries}

depends on the imported prices. As we can see from Fig. 13(d), there is an obvious negative relationship between imported prices and $\mathrm{EROI}_{I O G}$. In order to undertake a more meticulous studies, the EROIs of different imported countries are calculated. The results from 2012 to 2015 are shown in Fig. 14 (more results are show in Table A7-A8). 
From Fig. 14, we can conclude that: 1) Overall, EROI ER $_{I}$ is higher than $\mathrm{EROI}_{I O}$. To be specific, $\mathrm{EROI}_{I G}$ of pipeline gas $\left(\mathrm{EROI}_{P G}\right)$ is the highest in 2015, $\mathrm{EROI}_{I G}$ of LNG $\left(\mathrm{EROI}_{L N G}\right)$ ranked the second, and the $\mathrm{EROI}_{I O}$ is the smallest. 2) The unit imported price has a negative relationship with EROI. As we can see from Fig. 14, the higher the imported price is, the lower the EROI is. 3) Combined with data in Table A7 and A8, we conclude that from the perspective of China, Australia LNG had the highest EROI $_{L N G}$ in all LNG exporters, Kazakhstan pipeline gas had the highest $\mathrm{EROI}_{P G}$ in all pipeline exporters, and the USA crude oil had the highest $\mathrm{EROI}_{I O}$ in the past five years. Besides the average EROIs of the long-cooperation exporters (who export OG to China since 1997) were similar, and were about 5. The average EROIs of crude oil from Venezuela, Columbia and Mexico reached to 6, while the average EROIs of crude oil from Thailand and Algeria were just about 4.

The bubble size in Fig. 14 reflects the imported volume. It is obvious that a large percent of IOG resources are imported from countries with low EROI ${ }_{I O G}$. Therefore, China should cogitate how to enhance the $\mathrm{EROI}_{I O G}$ by optimizing the import structure. Australia, Kazakhstan, and the USA should be prioritized in the optimization process.

$<$ Figure 14 here >

\section{Conclusions and policy recommendations}

By applying EROI to analyze the DOG, offshore DOG, onshore DOG, and IOG, we conclude that: 1) Overall, the EROIs of DOG were higher than those of IOG. 2) The EROIs of DOG and onshore DOG fluctuated in the range between 8.5 and 12.0 and the range between 8.2 to 13.5 respectively. The EROIs of offshore DOG decreased to 7.2 in 2013 but increased to 8.5 in 2014. The EROIs of IOG were fluctuating. 3) The EROI change tendency was decided by EROIs of crude oil, EROIs of natural gas, and gas production percentage. 4) The EROIs of IOG had a clear negative relationship with imported price. 
The EROIs of LNG and pipeline gas was higher than those of crude oil; 5) From an EROI perspective, China should prioritize Australia, Kazakhstan, and the USA if optimizing the energy features of its import structure.

Based on the results, several suggestions are proposed here:

(1) Encouraging the development of DOG, especially the natural gas. The EROIs of DOG outnumbered the EROIs of IOG. Therefore, the government should take different methods to stimulate the investment in the DOG. There are two ways to promote the development of the DOG. On one hand, China should push its marketization reform on the price mechanism of oil and gas products and access mechanism of the upstream oil and gas industry. By apoting this method, the government can rely on the "invisible hand" of the market economy. More enterprises will participate in the DOG industry, which in return intensifies the competition and improve the efficiency. Besides, the governments can provide subsidies, investment compensation, and low-interest loan to attract private capitals to involve in DOG industry.

China should pay more attention to the development of natural gas because the EROIs of natural gas were relatively high. The development of natural gas in China is still in early stage. Therefore, the infrastructure of natural gas is inadequate, such as the pipeline, the storage tanks and so on. Besides, the application of natural gas is usually limited to chemical industry, and cooking and heating for residents. Therefore, to facilitate the development of natural gas, the government should make plans for the construction of natural gas infrastructure, and encourage the development of the distributed generation using natural gas, the use LNG or natural gas fuel, and the civil use.

(2) Optimizing the imported structure of IOG. Although the EROIs of IOG were low compared to that of DOG, China still needs to import plenty of oil and gas (especially the natural gas) to fill the gaps between demand and domestic supply. Besides, the potential of oil and gas in China is limited. Therefore, China should continue to import oil and gas. 
However, as the IOG from different countries generates different EROIs, China should optimize the imported structure. From an EROI perspective, China should prioritize Australia, Kazakhstan, and the USA if optimizing the energy features of its import structure. Moreover, the government could make use of the "one belt and one road" strategy when importing the oil and gas because the EROIs of oil and gas producers, which locate in the rang of "one belt and one road", are relatively high. Therefore, China can reinforce energy cooperation with these oil and gas producers. Meanwhile, China should promote the construction of oil and gas pipeline and LNG receiving stations in order to import more oil and gas.

(3) Developing environmental technologies. Air emissions receive more and more attention as people start to stress the sustainability of the world and economy, and they have negative impacts on EROIs. As both DOG and IOG generate air emission, environmental technologies should be applied in the process of both DOG and IOG, despite that the use of such technologies will increase the energy inputs and decrease the EROI. To be specific, the government can promote the application of the existing technologies, such as carbon capture and storage. Moreover, the government could develop sophisticated technologies which can lower the costs and energy consumption of the current technologies.

\section{Acknowledgments}

This work is supported by the Young Fund of Shanxi University of Finance and Economics (No. QN-2018002), National Natural Science Foundation of China (No. 71774105) and Shanxi Repatriate Study Abroad Foundation (No. 2016-3). 


\section{Appendix A}

$<$ Table A1-A9 here >

\section{References}

Arvesen, A., Hertwich, E.G., 2015. More caution is needed when using life cycle assessment to determine energy return on investment (EROI). Energy Policy 76, 1-6.

Atlason, R., Unnthorsson, R., 2014. Ideal EROI (energy return on investment) deepens the understanding of energy systems. Energy 67, 241-245.

Aucott, M., Hall, C., 2014. Does a change in price of fuel affect GDP growth? An examination of the U.S. data from 1950-2013. Energies 7, 6558-6570.

Beal, C.M., Hebner, R.E., Webber, M.E., Ruoff, R.S., Seibert, A.F., King, C.W., 2012. Comprehensive evaluation of algal biofuel production: Experimental and target results. Energies 5, 1943-1981.

BP. BP energy outlook 2035; BP p.l.c.: London, UK, 2015.

BP. BP statistical review of world energy 2016; BP p.l.c.: London, UK, 2016.

Brand-Correa, L., Brockway, P., Copeland, C., Foxon, T., Owen, A., Taylor, P., 2017. Developing an Input-Output Based Method to Estimate a National-Level Energy Return on Investment (EROI). Energies 10, 534.

Brandt, A.R., 2011. Oil depletion and the energy efficiency of oil production: The case of California. Sustainability 3, 1833-1854.

Brandt, A.R., Dale, M., 2011. A general mathematical framework for calculating systems-scale efficiency of energy extraction and conversion energy return on investment (EROI) and other energy return ratios. Energies 4, 1211-1245.

Brandt, A.R., Dale, M., Barnhart, C.J., 2013. Calculating systems-scale energy efficiency and net energy returns: A bottom-up matrix-based approach. Energy 62, 235-247.

Brandt, A.R., Englander, J., Bharadwaj, S., 2013. The energy efficiency of oil sands extraction: Energy return ratios from 1970 to 2010. Energy 55, 693-702.

Brandt, A.R., Yeskoo, T., Vafi, K., 2015. Net energy analysis of Bakken crude oil production using a well-level engineering-based model. Energy 93, 2191-2198.

Chen, Y., Feng, L., Wang, J., Höök, M., 2017. Emergy-based energy return on investment method for evaluating energy exploitation. Energy 128, 540-549.

Cleveland, C., 2005. Net energy from the extraction of oil and gas in the United States. Energy 30, 769-782.

Cleveland, C.J., Costanza, R., Hall, C.A.S., Kaufmann, R., 1984. Energy and the U.S. Economy: A Biophysical Perspective. Science 225, 890-897.

Cleveland, C.J., O Connor, P.A., 2011. Energy Return on Investment (EROI) of Oil Shale. Sustainability 3, 2307-2322. 
Court, V., Fizaine, F., 2017. Long-Term Estimates of the Energy-Return-on-Investment (EROI) of Coal, Oil, and Gas Global Productions. Ecological Economics 138, 145-159.

Dale, M., Krumdieck, S., Bodger, P., 2011a. A dynamic function for energy return on investment. Sustainability 3, 1972-1985.

Dale, M., Krumdieck, S., Bodger, P., 2011b. Net energy yield from production of conventional oil. Energy Policy 39, 7095-7102.

Dupont, E., Koppelaar, R., Jeanmart, H., 2018. Global available wind energy with physical and energy return on investment constraints. Applied Energy 209, 322-338.

Feng, J., Feng, L., Wang, J., 2018. Analysis of Point-of-Use Energy Return on Investment and Net Energy Yields from China's Conventional Fossil Fuels. Energies 11, 313.

Feng, J., Feng, L., Wang, J., King, C.W., 2018. Modeling the point of use EROI and its implications for economic growth in China. Energy 144, 232-242.

Font De Mora, E., Torres, C., Valero, A., 2012. Assessment of biodiesel energy sustainability using the exergy return on investment concept. Energy 45, 474-480.

Freise, J., 2011. The EROI of conventional Canadian natural gas production. Sustainability 3, 2080-2104.

Gagnon, N., Hall, C.A.S., Brinker, L., 2009. A Preliminary Investigation of Energy Return on Energy Investment for Global Oil and Gas Production. Energies 2, 490-503.

Gately, M., 2007. The EROI of U.S. offshore energy extraction: A net energy analysis of the Gulf of Mexico. Ecological Economics 63, 355-364.

Grandell, L., Hall, C.A.S., Höök, M., 2011. Energy return on investment for Norwegian oil and gas from 1991 to 2008. Sustainability 3, 2050-2070.

Guilford, M.C., Hall, C.A.S., O Connor, P., Cleveland, C.J., 2011. A New Long Term Assessment of Energy Return on Investment (EROI) for U.S. Oil and Gas Discovery and Production. Sustainability 3, 1866-1887.

Gupta, A.K., Hall, C.A.S., 2011. A Review of the Past and Current State of EROI Data. Sustainability 3, 1796-1809.

Hall, A.S.C., Balogh, S., Murphy, D.J.R., 2009. What is the minimum EROI that a sustainable society must have? Energies 2, 25-47.

Hall, C., Cleveland, C., Kaufmann, R., 1986. Energy and Resource Quality: The Ecology of the Economic Process. Wiley-InterScience, New York, NY, USA.

Hall, C., Lavine, M., Sloane, J., 1979. Efficiency of energy delivery systems: I. An economic and energy analysis. Environ. Manage. 3, 493-504.

Hall, C.A.S., 1972. Migration and Metabolism in a Temperate Stream Ecosystem. Ecology 53, 585-604

Hall, C.A.S., Cleveland, C.J., 1981. Petroleum Drilling and Production in the United States: Yield per Effort and Net Energy Analysis. Science 211, 576-579.

Hall, C.A.S., Lambert, J.G., Balogh, S.B., 2014. EROI of different fuels and the implications for society. Energy Policy 64, 141-152.

Henshaw, P.F., King, C., Zarnikau, J., 2011. System Energy Assessment (SEA), Defining a Standard Measure of EROI for Energy Businesses as Whole Systems. Sustainability 3, 1908-1943.

Heun, M.K., de Wit, M., 2012. Energy return on (energy) invested (EROI), oil prices, and energy transitions. Energy Policy 40, 147-158. 
Hu, Y., Feng, L., Hall, C.C.S., Tian, D., 2011. Analysis of the energy return on investment (EROI) of the huge Daqing oil field in China. Sustainability 3, 2323-2338.

Hu, Y., Hall, C.A.S., Wang, J., Feng, L., Poisson, A., 2013. Energy Return on Investment (EROI) of China's conventional fossil fuels: Historical and future trends. Energy 54, 352-364.

Huang, Y., Gan, X., Chiueh, P., 2017. Life cycle assessment and net energy analysis of offshore wind power systems. Renewable Energy 102, 98-106.

Kessides, I.N., Wade, D.C., 2011. Deriving an improved dynamic EROI to provide better information for energy planners. Sustainability 3, 2339-2357.

King, C.W., Hall, C.A.S., 2011. Relating Financial and Energy Return on Investment. Sustainability 3, 1810-1832.

Kittner, N., Gheewala, S.H., Kammen, D.M., 2016. Energy return on investment (EROI) of mini-hydro and solar PV systems designed for a mini-grid. Renewable Energy 99, 410-419.

Kong, Z., Dong, X., Liu, G., 2016. Coal-based synthetic natural gas vs. imported natural gas in China: a net energy perspective. J. Clean. Prod. 131, 690-701.

Kong, Z., Dong, X., Xu, B., Li, R., Yin, Q., Song, C., 2015. EROI Analysis for Direct Coal Liquefaction without and with CCS: The Case of the Shenhua DCL Project in China. Energies $8,786-807$.

Kunz, H., Hagens, N., Balogh, S., 2014. The influence of output variability from renewable electricity generation on net energy calculations. Energies 7, 150-172.

Lambert, J.G., Hall, C.A.S., Balogh, S., Gupta, A., Arnold, M., 2014. Energy, EROI and quality of life. Energy Policy 64, 153-167.

Leccisi, E., Raugei, M., Fthenakis, V., 2016. The energy and environmental performance of ground-mounted photovoltaic systems-A timely update. Energies 9, 622.

Li, X., Ou, X., Zhang, X., Zhang, Q., Zhang, X., 2013. Life-cycle fossil energy consumption and greenhouse gas emission intensity of dominant secondary energy pathways of China in 2010. Energy 50, 15-23.

LMT, 2015. Ship emissions calculator. Laboratory for Maritime Transport (LMT) of National Technical University of Athens.

Moerschbaecher, M., Day Jr., J.W., 2011. Ultra-Deepwater Gulf of Mexico Oil and Gas: Energy Return on Financial Investment and a Preliminary Assessment of Energy Return on Energy Investment. Sustainability 3, 2009-2026.

Murphy, D., Carbajales-Dale, M., Moeller, D., 2016. Comparing Apples to Apples: Why the Net Energy Analysis Community Needs to Adopt the Life-Cycle Analysis Framework. Energies 9, 917.

Murphy, D.J., Hall, C.A.S., 2011. Energy return on investment, peak oil, and the end of economic growth. Ann. NY. Acad. Sci. 1219, 52-72.

Murphy, D.J., Hall, C.A.S., Dale, M., Cleveland, C., 2011. Order from chaos: A preliminary protocol for determining the EROI of fuels. Sustainability 3, 1888-1907.

Neumeyer, C., Goldston, R., 2016. Dynamic EROI Assessment of the IPCC 21st Century Electricity Production Scenario. Sustainability 8, 421.

Nogovitsyn, R., Sokolov, A., 2014. Preliminary calculation of the EROI for the production of gas in Russia. Sustainability 6, 6751-6765.

Pa, A., Bi, X.T., Sokhansanj, S., 2013. Evaluation of wood pellet application for residential heating 
Tables:

Table 1 describes the energy equivalent of different energy carriers.

Table 1.

Thermal energy equivalent of different energies.

\begin{tabular}{|c|c|}
\hline Energy & Energy equivalent \\
\hline Crude oil & $41.8 \mathrm{MJ} / \mathrm{kg}$ \\
\hline Gasoline & $43.1 \mathrm{MJ} / \mathrm{kg}$ \\
\hline Kerosene & $43.1 \mathrm{MJ} / \mathrm{kg}$ \\
\hline Diesel & $42.7 \mathrm{MJ} / \mathrm{kg}$ \\
\hline Fuel Oil & $41.8 \mathrm{MJ} / \mathrm{kg}$ \\
\hline Liquefied Petroleum Gas (LPG) & $50.2 \mathrm{MJ} / \mathrm{kg}$ \\
\hline Refinery Gas & $46.0 \mathrm{MJ} / \mathrm{kg}$ \\
\hline Other Petroleum Products (OPP) ${ }^{1}$ & $41.8 \mathrm{MJ} / \mathrm{kg}$ \\
\hline Natural Gas & $35.6 \mathrm{MJ} / \mathrm{m}^{3}$ \\
\hline Liquefied Natural Gas (LNG) ${ }^{2}$ & $51.2 \mathrm{MJ} / \mathrm{kg}$ \\
\hline Heat & $1.0 \mathrm{MJ} / \mathrm{MJ}$ \\
\hline Electricity & $3.6 \mathrm{MJ} / \mathrm{kWh}$ \\
\hline Other Energy $(\mathrm{OE})^{3}$ & $29.3 \mathrm{MJ} / \mathrm{kg}$ \\
\hline Raw Coal & $20.9 \mathrm{MJ} / \mathrm{kg}$ \\
\hline
\end{tabular}

${ }^{1}$ The energy equivalent of other petroleum products is assumed to be the same as that of crude oil.

${ }^{2}$ One million tons LNG equals to 1.224 million tons of oil equivalent (BP).

${ }^{3}$ Other energy is counted by standard coal in China Energy Statistical Yearbook. Therefore the energy equivalent of standard coal is applied.

MJ is megajoule, namely $10^{6}$ joules.

Data source: China Energy Statistical Yearbook.

Table 2 describes raw data and the energy outputs of the entire DOG.

Table 2.

Energy outputs for the entire DOG.

\begin{tabular}{|c|c|c|c|c|c|}
\hline \multirow[t]{2}{*}{ Year } & \multicolumn{2}{|l|}{ Crude oil } & \multicolumn{2}{|c|}{ Natural gas } & \multirow{2}{*}{$\begin{array}{l}\text { Total } \\
\text { Energy } \\
\text { EJ }\end{array}$} \\
\hline & $\begin{array}{l}\text { Raw data } \\
10^{6} \text { tons }\end{array}$ & $\begin{array}{l}\text { Energy } \\
\text { Exajoule (EJ) }\end{array}$ & $\begin{array}{l}\text { Raw data } \\
10^{9} \mathrm{~m}^{3}\end{array}$ & $\begin{array}{l}\text { Energy } \\
\text { EJ }\end{array}$ & \\
\hline 1997 & 161 & 6.7 & 23 & 0.8 & 7.5 \\
\hline 1998 & 161 & 6.7 & 23 & 0.8 & 7.6 \\
\hline 1999 & 160 & 6.7 & 25 & 0.9 & 7.6 \\
\hline 2000 & 163 & 6.8 & 27 & 1.0 & 7.8 \\
\hline 2001 & 164 & 6.9 & 30 & 1.1 & 7.9 \\
\hline 2002 & 167 & 7.0 & 33 & 1.2 & 8.1 \\
\hline 2003 & 170 & 7.1 & 35 & 1.2 & 8.3 \\
\hline 2004 & 176 & 7.4 & 41 & 1.5 & 8.8 \\
\hline 2005 & 181 & 7.6 & 49 & 1.8 & 9.3 \\
\hline 2006 & 185 & 7.7 & 59 & 2.1 & 9.8 \\
\hline 2007 & 186 & 7.8 & 69 & 2.5 & 10.3 \\
\hline 2008 & 190 & 8.0 & 80 & 2.9 & 10.8 \\
\hline 2009 & 189 & 7.9 & 85 & 3.0 & 11.0 \\
\hline 2010 & 202 & 8.5 & 96 & 3.4 & 11.9 \\
\hline 2011 & 203 & 8.5 & 105 & 3.7 & 12.2 \\
\hline 2012 & 207 & 8.7 & 111 & 3.9 & 12.6 \\
\hline 2013 & 210 & 8.8 & 121 & 4.3 & 13.1 \\
\hline 2014 & 211 & 8.8 & 130 & 4.6 & 13.5 \\
\hline
\end{tabular}

Data Source: China Statistical Yearbook. 
Table 3 describes the energy inputs of the entire DOG.

Table 3.

Energy input of the entire DOG.

\begin{tabular}{llll}
\hline \multirow{2}{*}{ Year } & Direct inputs & Indirect inputs & Total inputs \\
\cline { 2 - 4 } & EJ & EJ & EJ \\
\hline 1997 & 0.68 & 0.07 & 0.75 \\
1998 & 0.64 & 0.08 & 0.71 \\
1999 & 0.69 & 0.07 & 0.76 \\
2000 & 0.77 & 0.08 & 0.84 \\
2001 & 0.82 & 0.09 & 0.90 \\
2002 & 0.84 & 0.10 & 0.95 \\
2003 & 0.86 & 0.16 & 1.02 \\
2004 & 0.74 & 0.18 & 0.91 \\
2005 & 0.74 & 0.23 & 0.97 \\
2006 & 0.77 & 0.29 & 1.06 \\
2007 & 0.80 & 0.25 & 1.05 \\
2008 & 0.85 & 0.33 & 1.18 \\
2009 & 0.82 & 0.40 & 1.22 \\
2010 & 0.87 & 0.38 & 1.25 \\
2011 & 0.83 & 0.29 & 1.13 \\
2012 & 0.82 & 0.25 & 1.07 \\
2013 & 0.88 & 0.25 & 1.14 \\
2014 & 0.91 & 0.26 & 1.17 \\
\hline
\end{tabular}

Table 4 describes the raw data and energy outputs of offshore DOG.

Table 4.

Energy outputs for offshore DOG.

\begin{tabular}{|c|c|c|c|c|c|}
\hline \multirow[t]{2}{*}{ Year } & \multicolumn{2}{|c|}{ Offshore crude oil } & \multicolumn{2}{|c|}{ Offshore natural gas } & \multirow{2}{*}{$\begin{array}{l}\text { Total offshore } \\
\text { Energy } \\
\text { EJ }\end{array}$} \\
\hline & $\begin{array}{l}\text { Raw data } \\
10^{6} \text { tons }\end{array}$ & $\begin{array}{l}\text { Energy } \\
\text { EJ }\end{array}$ & $\begin{array}{l}\text { Raw data } \\
10^{9} \mathrm{~m}^{3}\end{array}$ & $\begin{array}{l}\text { Energy } \\
\text { EJ }\end{array}$ & \\
\hline 1997 & 20 & 0.8 & 4 & 0.2 & 1.0 \\
\hline 1998 & 19 & 0.8 & 4 & 0.1 & 0.9 \\
\hline 1999 & 19 & 0.8 & 5 & 0.2 & 1.0 \\
\hline 2000 & 21 & 0.9 & 5 & 0.2 & 1.0 \\
\hline 2001 & 21 & 0.9 & 5 & 0.2 & 1.1 \\
\hline 2002 & 24 & 1.0 & 5 & 0.2 & 1.2 \\
\hline 2003 & 25 & 1.1 & 4 & 0.2 & 1.2 \\
\hline 2004 & 28 & 1.2 & 6 & 0.2 & 1.4 \\
\hline 2005 & 32 & 1.3 & 6 & 0.2 & 1.6 \\
\hline 2006 & 32 & 1.4 & 7 & 0.3 & 1.6 \\
\hline 2007 & 32 & 1.3 & 8 & 0.3 & 1.6 \\
\hline 2008 & 34 & 1.4 & 9 & 0.3 & 1.7 \\
\hline 2009 & 37 & 1.5 & 9 & 0.3 & 1.9 \\
\hline 2010 & 47 & 2.0 & 11 & 0.4 & 2.4 \\
\hline 2011 & 45 & 1.9 & 12 & 0.4 & 2.3 \\
\hline 2012 & 44 & 1.9 & 12 & 0.4 & 2.3 \\
\hline 2013 & 45 & 1.9 & 12 & 0.4 & 2.3 \\
\hline
\end{tabular}


Data Source: China Marine Statistical Yearbook.

Table 5 describes the energy inputs of offshore DOG.

Table 5.

Energy inputs of offshore DOG.

\begin{tabular}{llll}
\hline Year & CNOOC inputs & Production percentage & Offshore inputs \\
\cline { 2 - 4 } & Petajoule (PJ) & $\%$ & PJ \\
\hline 1997 & 40 & $42 \%$ & 95 \\
1998 & 37 & $44 \%$ & 83 \\
1999 & 34 & $44 \%$ & 76 \\
2000 & 40 & $47 \%$ & 84 \\
2001 & 44 & $50 \%$ & 87 \\
2002 & 58 & $52 \%$ & 112 \\
2003 & 54 & $50 \%$ & 108 \\
2004 & 69 & $49 \%$ & 140 \\
2005 & 78 & $51 \%$ & 153 \\
2006 & 84 & $52 \%$ & 161 \\
2007 & 85 & $51 \%$ & 166 \\
2008 & 98 & $55 \%$ & 178 \\
2009 & 120 & $57 \%$ & 210 \\
2010 & 167 & $63 \%$ & 266 \\
2011 & 175 & $65 \%$ & 271 \\
2012 & 183 & $65 \%$ & 281 \\
2013 & 207 & $64 \%$ & 323 \\
2014 & 178 & $63 \%$ & 281 \\
\hline
\end{tabular}

Table 6 describes the raw data and energy outputs of onshore DOG.

Table 6.

Energy outputs for onshore DOG.

\begin{tabular}{|c|c|c|c|c|c|}
\hline \multirow[t]{3}{*}{ Year } & \multicolumn{2}{|c|}{ Onshore crude oil } & \multicolumn{2}{|c|}{ Onshore natural gas } & \multirow{3}{*}{$\begin{array}{l}\text { Total onshore } \\
\text { Energy } \\
\text { EJ }\end{array}$} \\
\hline & Raw data & Energy & Raw data & Energy & \\
\hline & $10^{6}$ tons & EJ & $10^{9} \mathrm{~m}^{3}$ & EJ & \\
\hline 1997 & 141 & 5.9 & 18 & 0.7 & 6.5 \\
\hline 1998 & 142 & 5.9 & 19 & 0.7 & 6.6 \\
\hline 1999 & 141 & 5.9 & 20 & 0.7 & 6.6 \\
\hline 2000 & 142 & 5.9 & 23 & 0.8 & 6.7 \\
\hline 2001 & 143 & 6.0 & 26 & 0.9 & 6.9 \\
\hline 2002 & 143 & 6.0 & 28 & 1.0 & 7.0 \\
\hline 2003 & 144 & 6.0 & 31 & 1.1 & 7.1 \\
\hline 2004 & 147 & 6.2 & 35 & 1.3 & 7.4 \\
\hline 2005 & 150 & 6.3 & 43 & 1.5 & 7.8 \\
\hline 2006 & 152 & 6.4 & 51 & 1.8 & 8.2 \\
\hline 2007 & 155 & 6.5 & 61 & 2.2 & 8.6 \\
\hline 2008 & 156 & 6.5 & 72 & 2.6 & 9.1 \\
\hline 2009 & 153 & 6.4 & 77 & 2.7 & 9.1 \\
\hline 2010 & 155 & 6.5 & 85 & 3.0 & 9.5 \\
\hline 2011 & 158 & 6.6 & 93 & 3.3 & 9.9 \\
\hline
\end{tabular}




\begin{tabular}{llllll}
2012 & 163 & 6.8 & 98 & 3.5 & 10.3 \\
2013 & 165 & 6.9 & 109 & 3.9 & 10.8 \\
2014 & 165 & 6.9 & 117 & 4.2 & 11.1 \\
\hline
\end{tabular}

Data Source: China Statistical Yearbook and China Marine Statistical Yearbook.

Table 7 describes the energy inputs of onshore DOG.

Table 7.

Energy input of onshore DOG.

\begin{tabular}{llll}
\hline Year & Total inputs & Offshore inputs & Onshore inputs \\
\cline { 2 - 4 } & EJ & EJ & EJ \\
\hline 1997 & 0.75 & 0.10 & 0.65 \\
1998 & 0.71 & 0.08 & 0.63 \\
1999 & 0.76 & 0.08 & 0.68 \\
2000 & 0.84 & 0.08 & 0.76 \\
2001 & 0.90 & 0.09 & 0.82 \\
2002 & 0.95 & 0.11 & 0.84 \\
2003 & 1.02 & 0.11 & 0.92 \\
2004 & 0.91 & 0.14 & 0.77 \\
2005 & 0.97 & 0.15 & 0.81 \\
2006 & 1.06 & 0.16 & 0.90 \\
2007 & 1.05 & 0.17 & 0.88 \\
2008 & 1.18 & 0.18 & 1.01 \\
2009 & 1.22 & 0.21 & 1.01 \\
2010 & 1.25 & 0.27 & 0.99 \\
2011 & 1.13 & 0.27 & 0.85 \\
2012 & 1.07 & 0.28 & 0.79 \\
2013 & 1.14 & 0.32 & 0.82 \\
2014 & 1.17 & 0.28 & 0.89 \\
\hline
\end{tabular}

Table 8 describes the raw data and energy outputs of IOG.

Table 8.

Energy outputs for IOG.

\begin{tabular}{|c|c|c|c|c|c|}
\hline \multirow[t]{2}{*}{ Year } & \multicolumn{2}{|c|}{ Imported crude oil } & \multicolumn{2}{|c|}{ Imported natural gas } & \multirow{2}{*}{$\begin{array}{l}\text { Total imported } \\
\text { Energy } \\
\text { EJ }\end{array}$} \\
\hline & $\begin{array}{l}\text { Raw data } \\
10^{6} \text { tons }\end{array}$ & $\begin{array}{l}\text { Energy } \\
\text { EJ }\end{array}$ & $\begin{array}{l}\text { Raw data } \\
10^{9} \mathrm{~m}^{3}\end{array}$ & $\begin{array}{l}\text { Energy } \\
\text { EJ }\end{array}$ & \\
\hline 1997 & 35 & 1.5 & 0 & 0.0 & 1.5 \\
\hline 1998 & 27 & 1.1 & 0 & 0.0 & 1.1 \\
\hline 1999 & 37 & 1.5 & 0 & 0.0 & 1.5 \\
\hline 2000 & 70 & 2.9 & 0 & 0.0 & 2.9 \\
\hline 2001 & 60 & 2.5 & 0 & 0.0 & 2.5 \\
\hline 2002 & 69 & 2.9 & 0 & 0.0 & 2.9 \\
\hline 2003 & 91 & 3.8 & 0 & 0.0 & 3.8 \\
\hline 2004 & 123 & 5.1 & 0 & 0.0 & 5.1 \\
\hline 2005 & 127 & 5.3 & 0 & 0.0 & 5.3 \\
\hline 2006 & 145 & 6.1 & 1 & 0.0 & 6.1 \\
\hline 2007 & 163 & 6.8 & 4 & 0.1 & 7.0 \\
\hline
\end{tabular}




\begin{tabular}{llllll}
2008 & 179 & 7.5 & 5 & 0.2 & 7.6 \\
2009 & 204 & 8.5 & 8 & 0.3 & 8.8 \\
2010 & 238 & 9.9 & 17 & 0.6 & 10.5 \\
2011 & 254 & 10.6 & 31 & 1.1 & 11.7 \\
2012 & 271 & 11.3 & 42 & 1.5 & 12.8 \\
2013 & 282 & 11.8 & 53 & 1.9 & 13.6 \\
2014 & 308 & 12.9 & 59 & 2.1 & 15.0 \\
\hline
\end{tabular}

Data Source: China Statistical Yearbook.

Table 9 describes the raw data and energy inputs of IOG.

Table 9.

Monetary inputs of IOG.

\begin{tabular}{|c|c|c|c|c|c|c|}
\hline \multirow[t]{3}{*}{ Year } & \multicolumn{4}{|l|}{ Raw data } & \multirow{3}{*}{$\begin{array}{l}\text { Convention factor } \\
\mathrm{E}_{\text {eint }} \\
\mathrm{MJ} / \mathrm{yuan}\end{array}$} & \multirow{3}{*}{$\begin{array}{l}\text { Total } \\
\text { Energy } \\
\text { PJ }\end{array}$} \\
\hline & Crude oil & LNG & Pipeline gas & Sub-total & & \\
\hline & $10^{6}$ yuan & $10^{6}$ yuan & $10^{6}$ yuan & $10^{6}$ yuan & & \\
\hline 1997 & 45,231 & & & 45,231 & 5.1 & 229 \\
\hline 1998 & 27,110 & & & 27,110 & 4.5 & 123 \\
\hline 1999 & 38,422 & & & 38,422 & 4.2 & 162 \\
\hline 2000 & 123,022 & & & 123,022 & 4.3 & 528 \\
\hline 2001 & 96,563 & & & 96,563 & 4.1 & 397 \\
\hline 2002 & 105,592 & & & 105,592 & 4.1 & 431 \\
\hline 2003 & 163,739 & & & 163,739 & 4.2 & 687 \\
\hline 2004 & 280,680 & & & 280,680 & 4.2 & 1,169 \\
\hline 2005 & 390,932 & & & 390,932 & 4.1 & 1,597 \\
\hline 2006 & 529,422 & 920 & & 530,343 & 3.8 & 2,027 \\
\hline 2007 & 606,578 & 4,567 & & 611,145 & 3.4 & 2,062 \\
\hline 2008 & 898,245 & 6,465 & & 904,709 & 2.9 & 2,657 \\
\hline 2009 & 609,705 & 8,634 & & 618,339 & 2.8 & 1,743 \\
\hline 2010 & 914,905 & 20,403 & 6,722 & 942,030 & 2.6 & 2,408 \\
\hline 2011 & $1,270,216$ & 37,226 & 30,044 & $1,337,486$ & 2.3 & 3,097 \\
\hline 2012 & $1,393,799$ & 51,940 & 50,133 & $1,495,872$ & 2.2 & 3,258 \\
\hline 2013 & $1,360,401$ & 65,757 & 61,121 & $1,487,278$ & 2.1 & 3,049 \\
\hline 2014 & $1,402,330$ & 75,211 & 71,343 & $1,548,885$ & 1.9 & 2,998 \\
\hline
\end{tabular}

Data Source: General Administration of Customs and China Statistics Yearbook. 


\section{Figures:}

Fig. 1. describes the GDP, oil and gas production, and consumption in China.

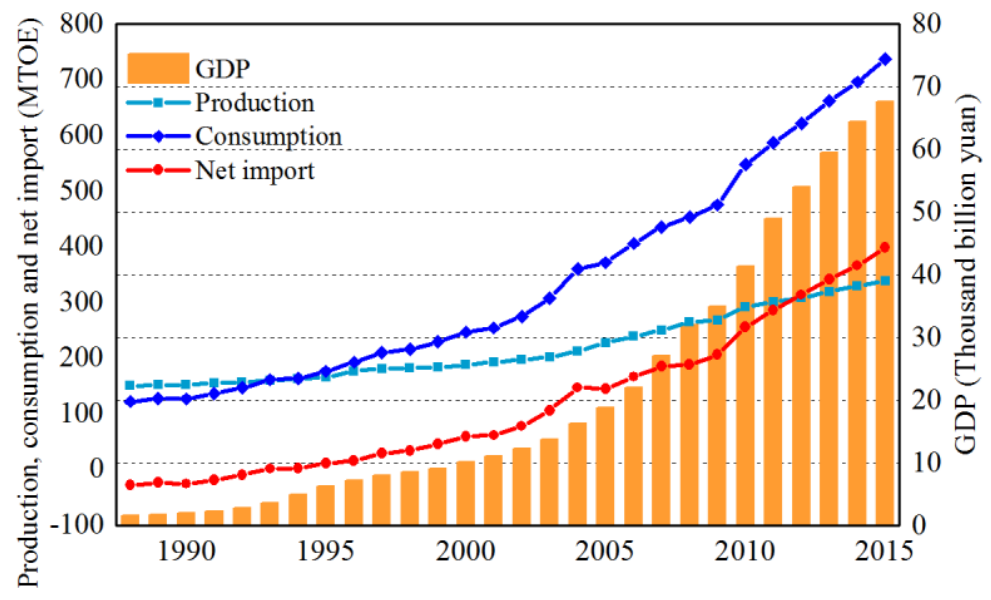

Fig. 1. GDP, oil and gas productions, and consumptions in China.

Fig. 2. describes supply mix of oil and gas in China in 2014.

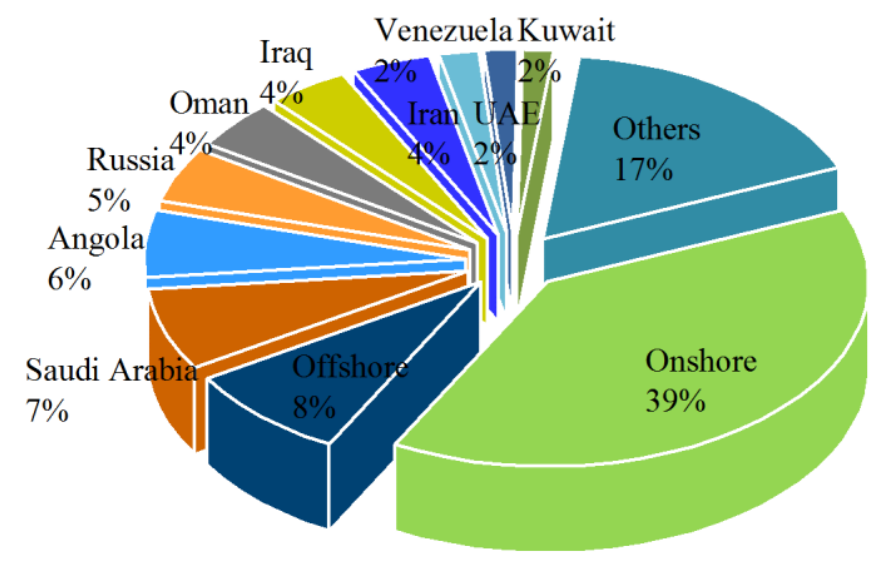

Fig. 2. Domestic production and key suppliers of oil and gas resources for China in 2014.

Fig. 3 describes the system boundary of the entire DOG. 


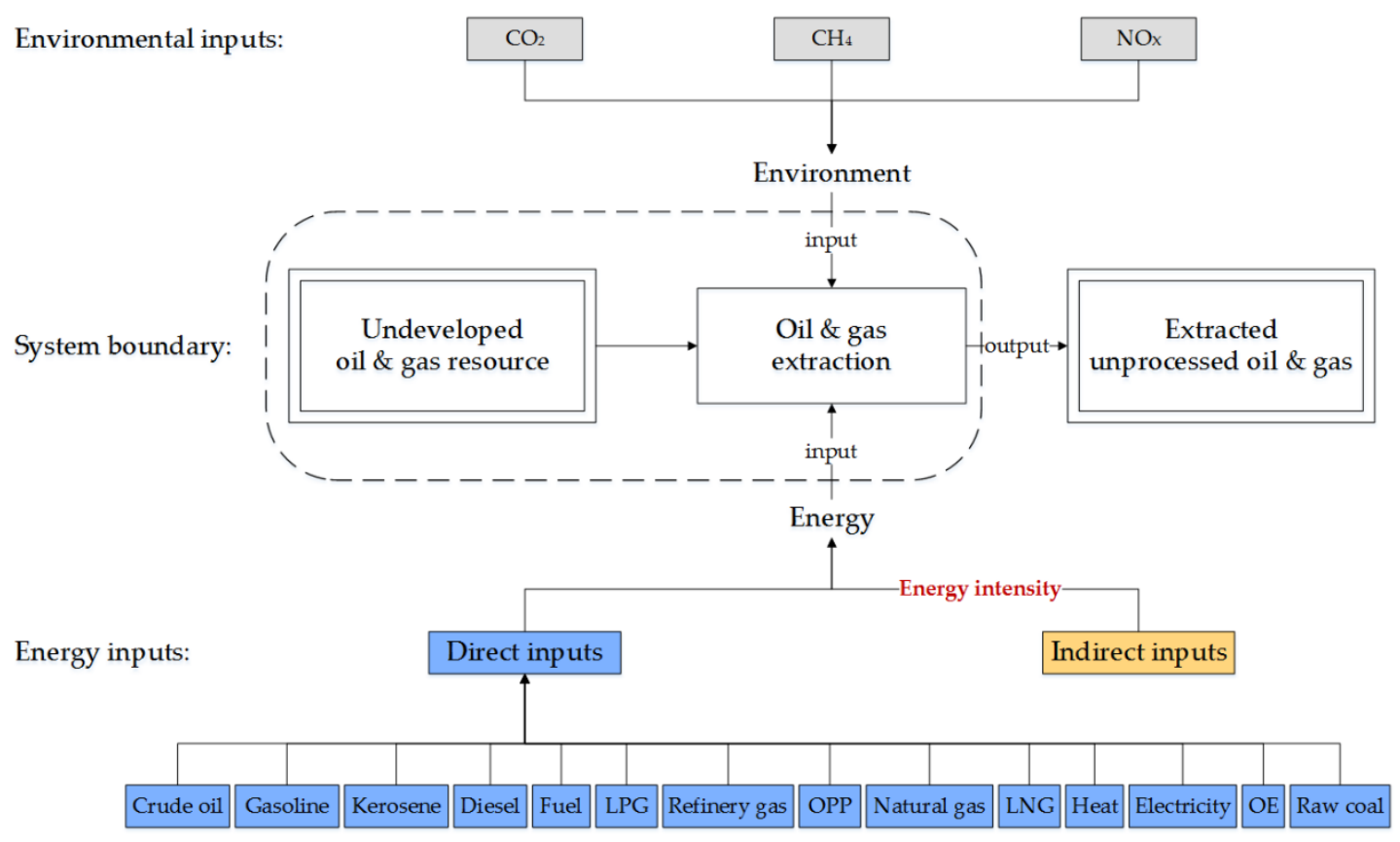

Fig. 3. System boundary of the entire DOG extraction process.

Fig. 4 describes the system boundary of offshore DOG.

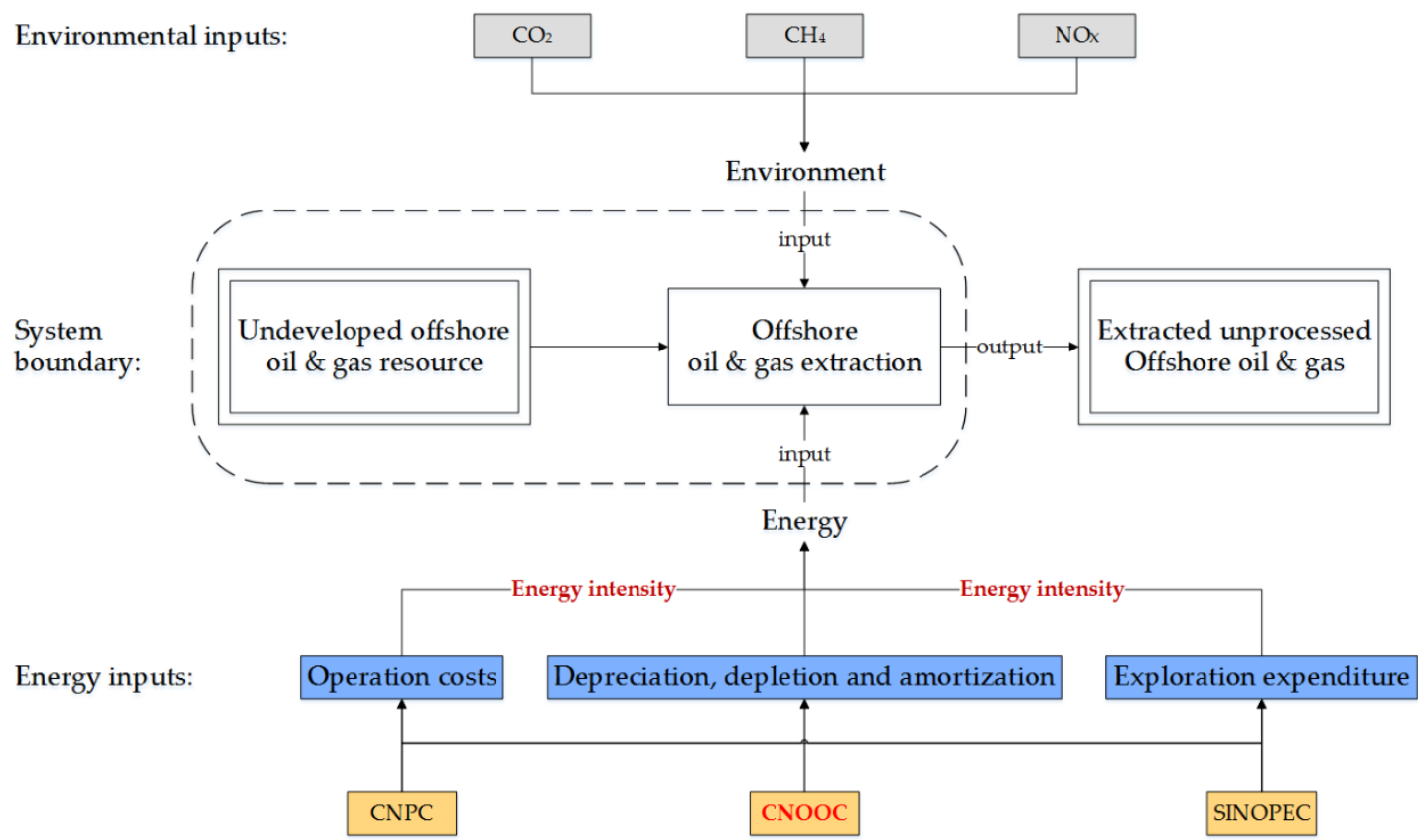

Fig. 4. System boundary of the offshore DOG extraction process.

Fig. 5 describes the system boundary of IOG. 


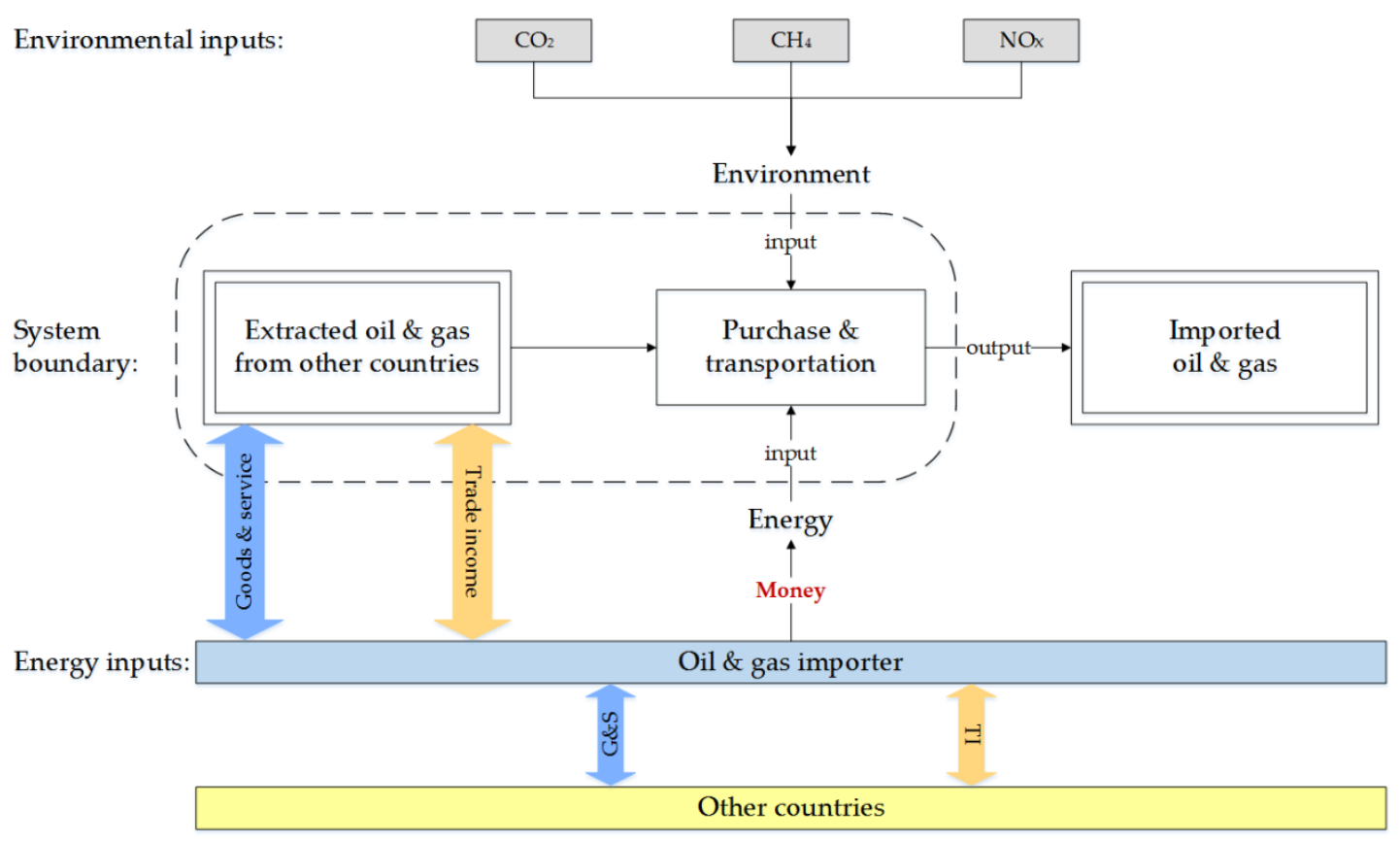

Fig. 5. System boundary of the IOG trade process.

Fig. 6 describes the energy intensity.

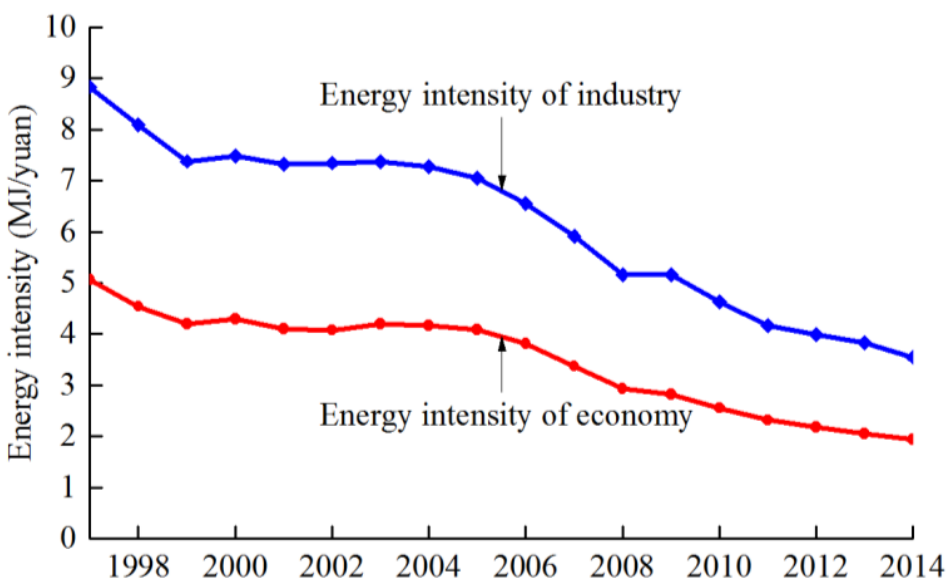

Fig. 6. Energy intensity of the industrial sector and the entire economy.

Fig. 7 describes the environmental inputs of the entire DOG. 


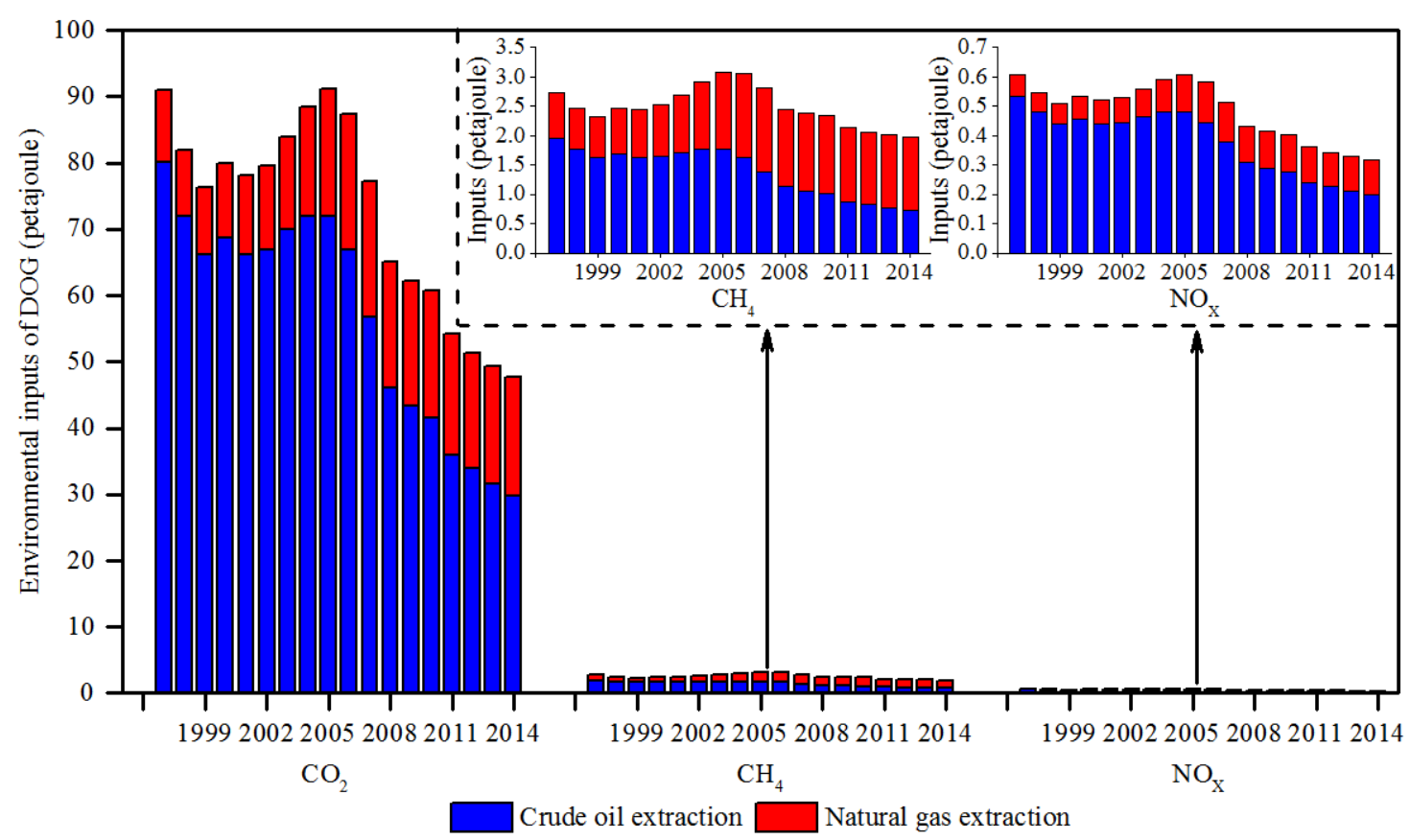

Fig. 7. Environmental inputs of the entire DOG.

Fig. 8 describes the environmental inputs of offshore DOG.

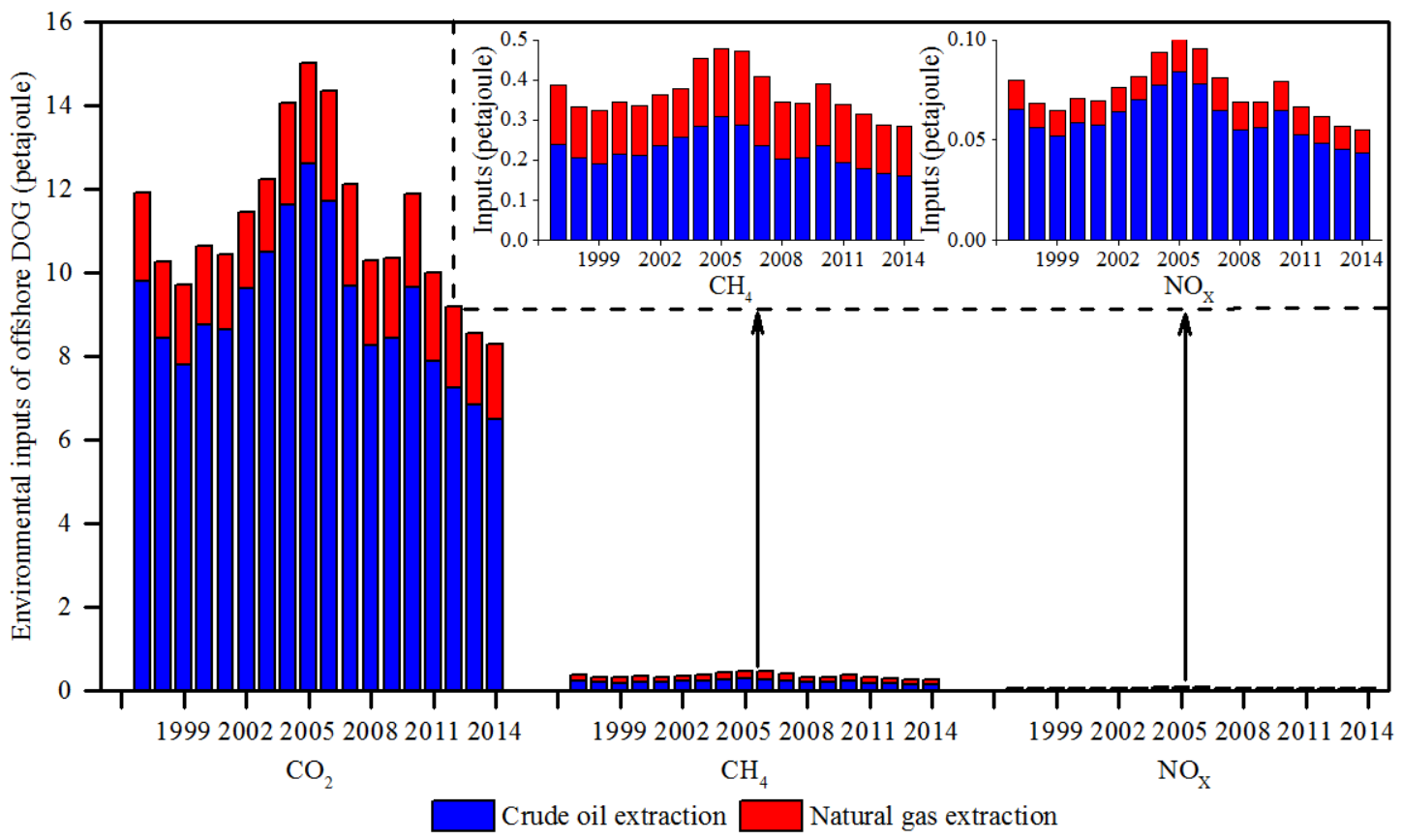

Fig. 8. Environmental inputs of offshore DOG.

Fig. 9 describes the environmental inputs of onshore DOG. 


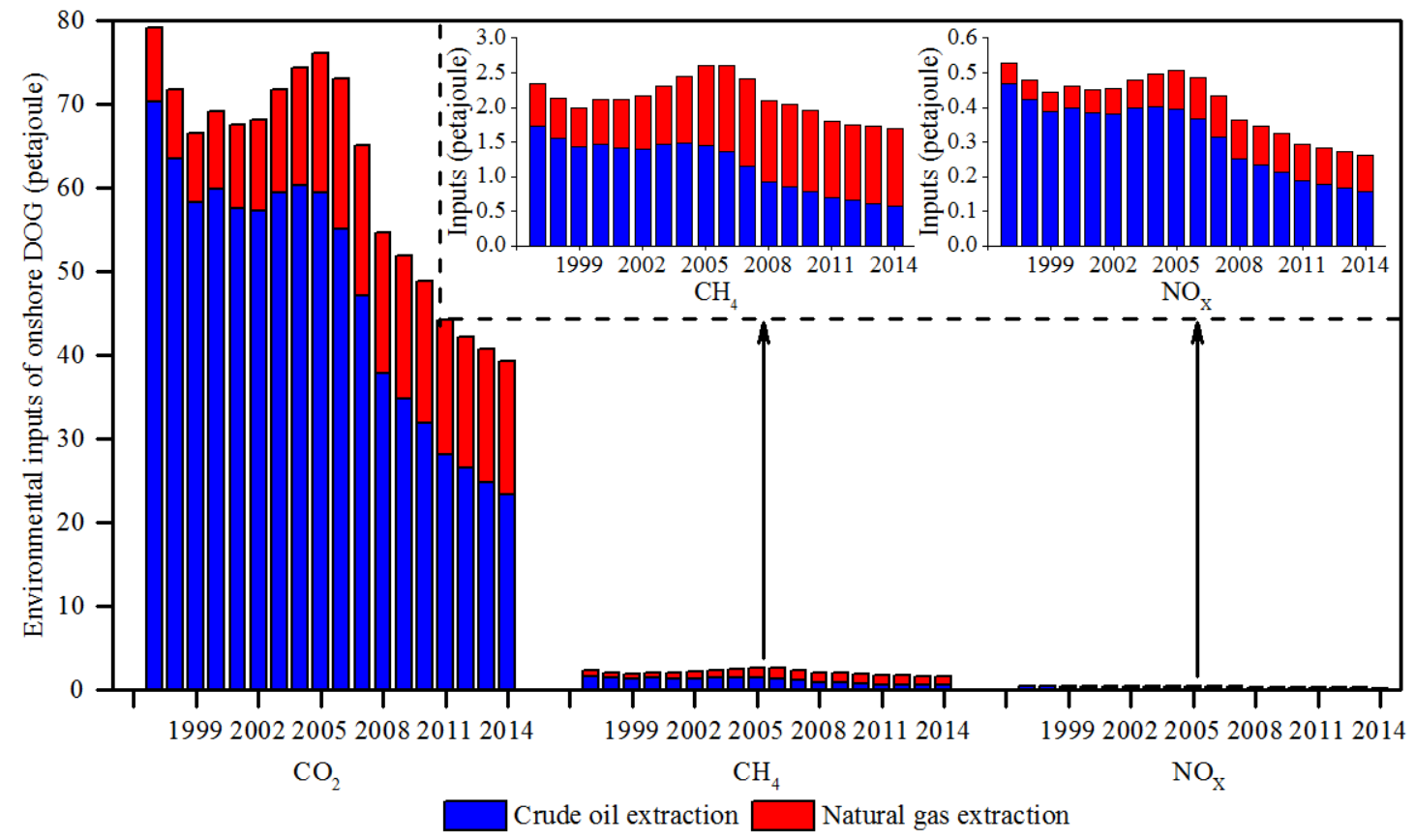

Fig. 9. Environmental inputs of onshore DOG.

Fig. 10 describes the environmental inputs of IOG.

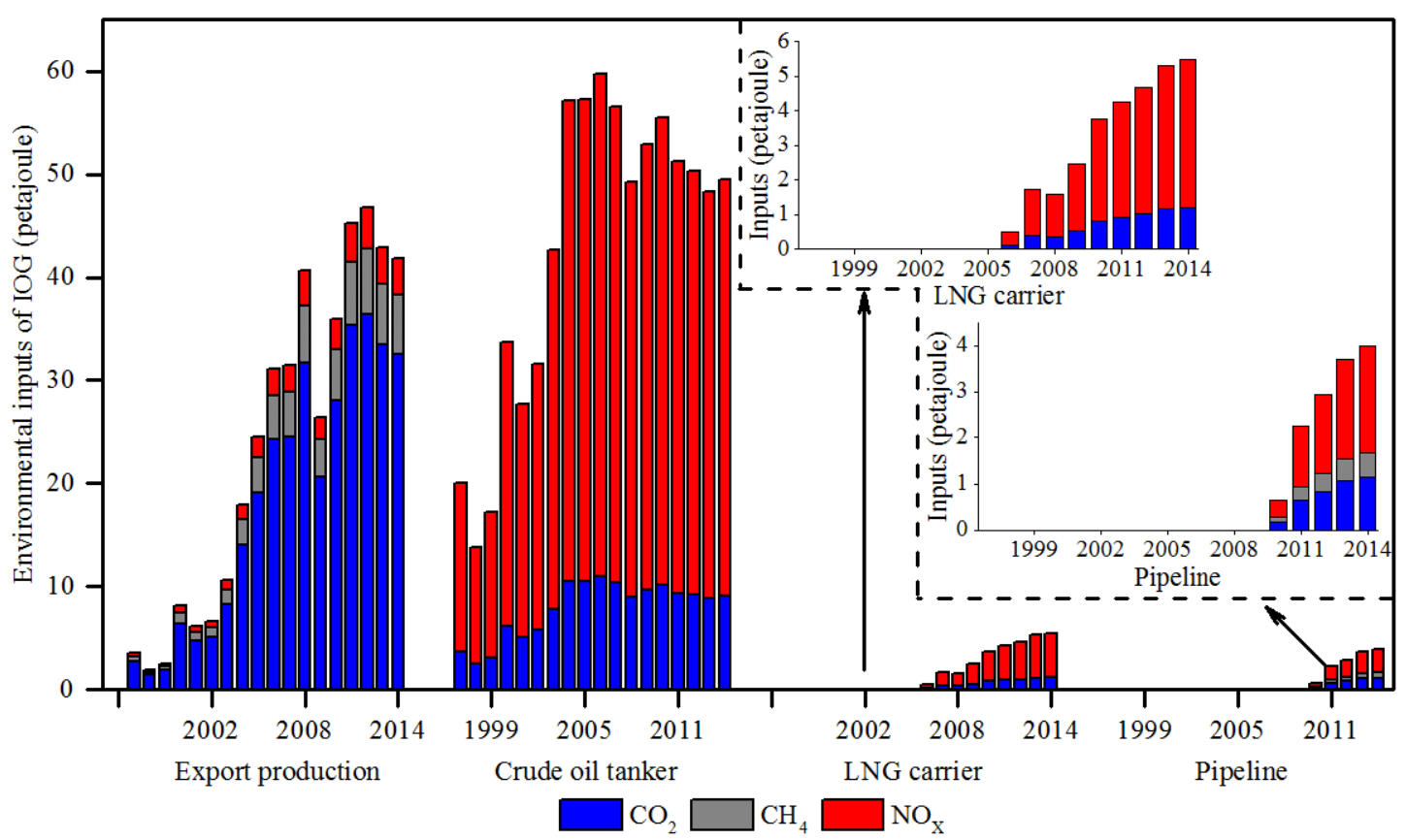

Fig. 10. Environmental inputs of IOG.

Fig. 11 describes the standard EROIs and EROIs with environmental inputs of the entire DOG, offshore DOG, onshore DOG and IOG. 

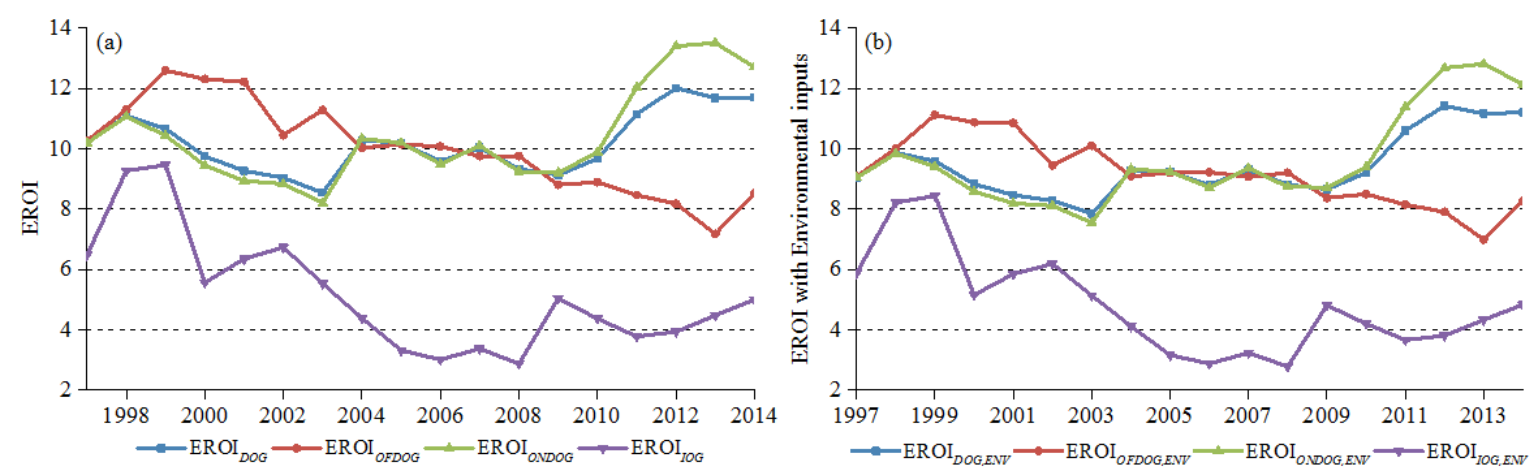

Fig. 11. EROIs of DOG, offshore DOG, onshore DOG, and IOG.

Fig. 12 describes the EROIs calculated by other scholars and our results.
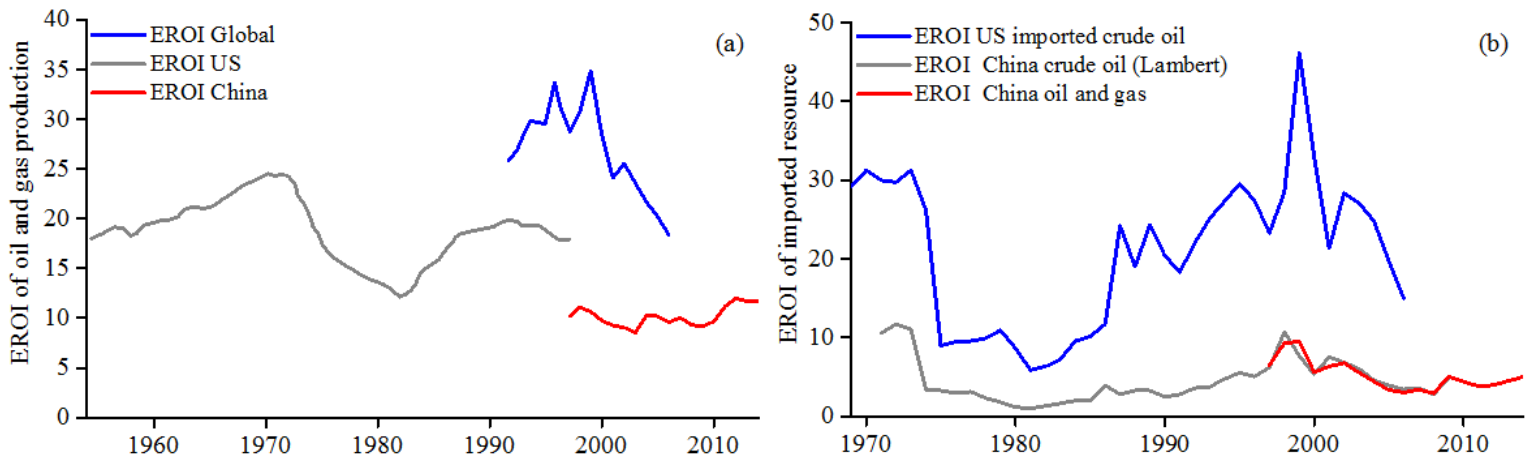

Fig. 12. Comparison with other EROI studies.

Fig. 13(a) describes the relationship between EROI and energy inputs. Fig. 13(b) describes the EROI of offshore DOG and monetary inputs. Fig. 13(c) describes the impacts of natural gas on EROIs of IOG. Fig. 13(d) describes the relationship between imported price and EROI of IOG.

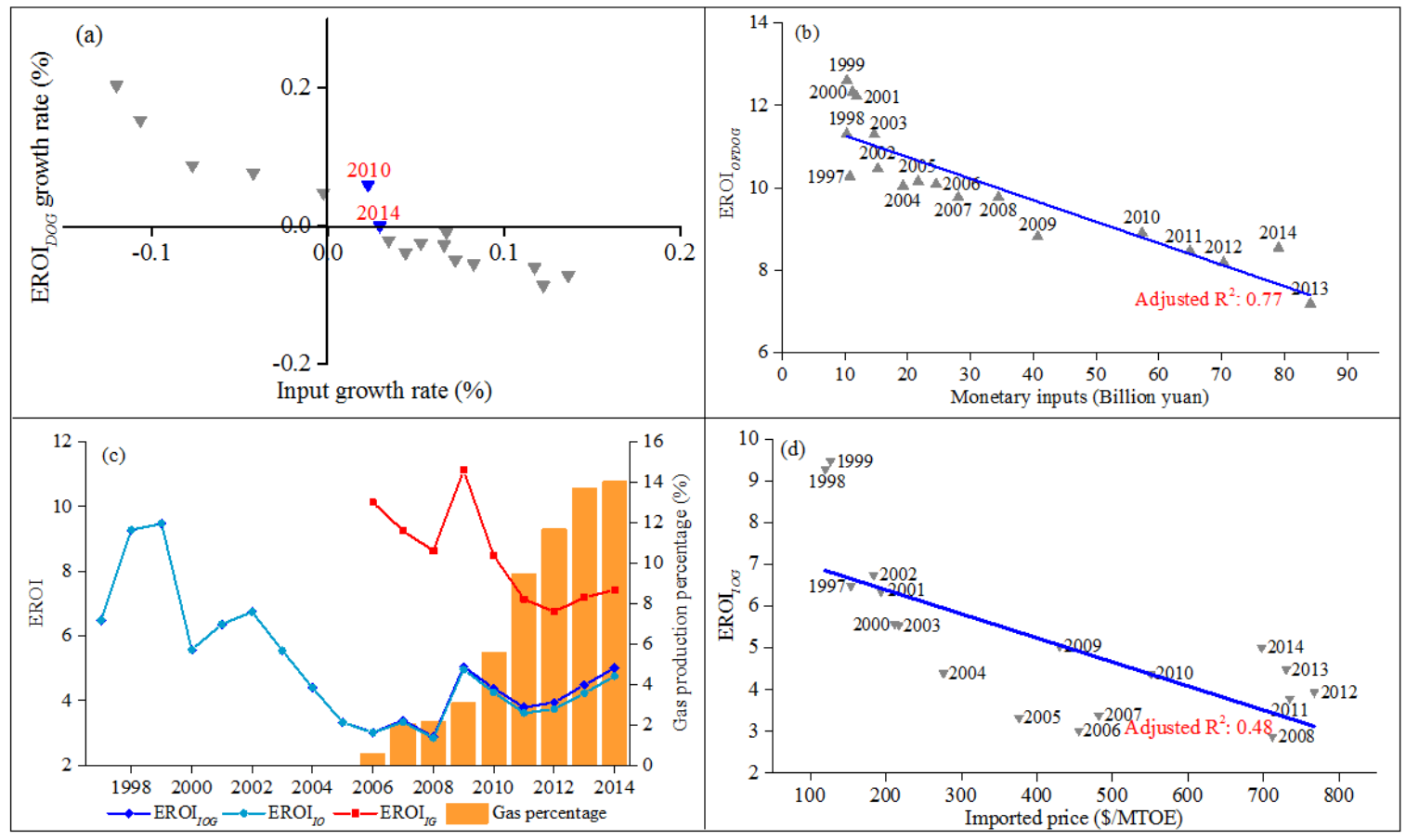

Fig. 13. The relationships among EROIs, gas percentage, unit price, energy inputs and monetary inputs. 
Fig. 14 describes the relationship between the unit price and EROIs of LNG, pipeline gas, and crude oil. The imported volumes are described by the bubble size.

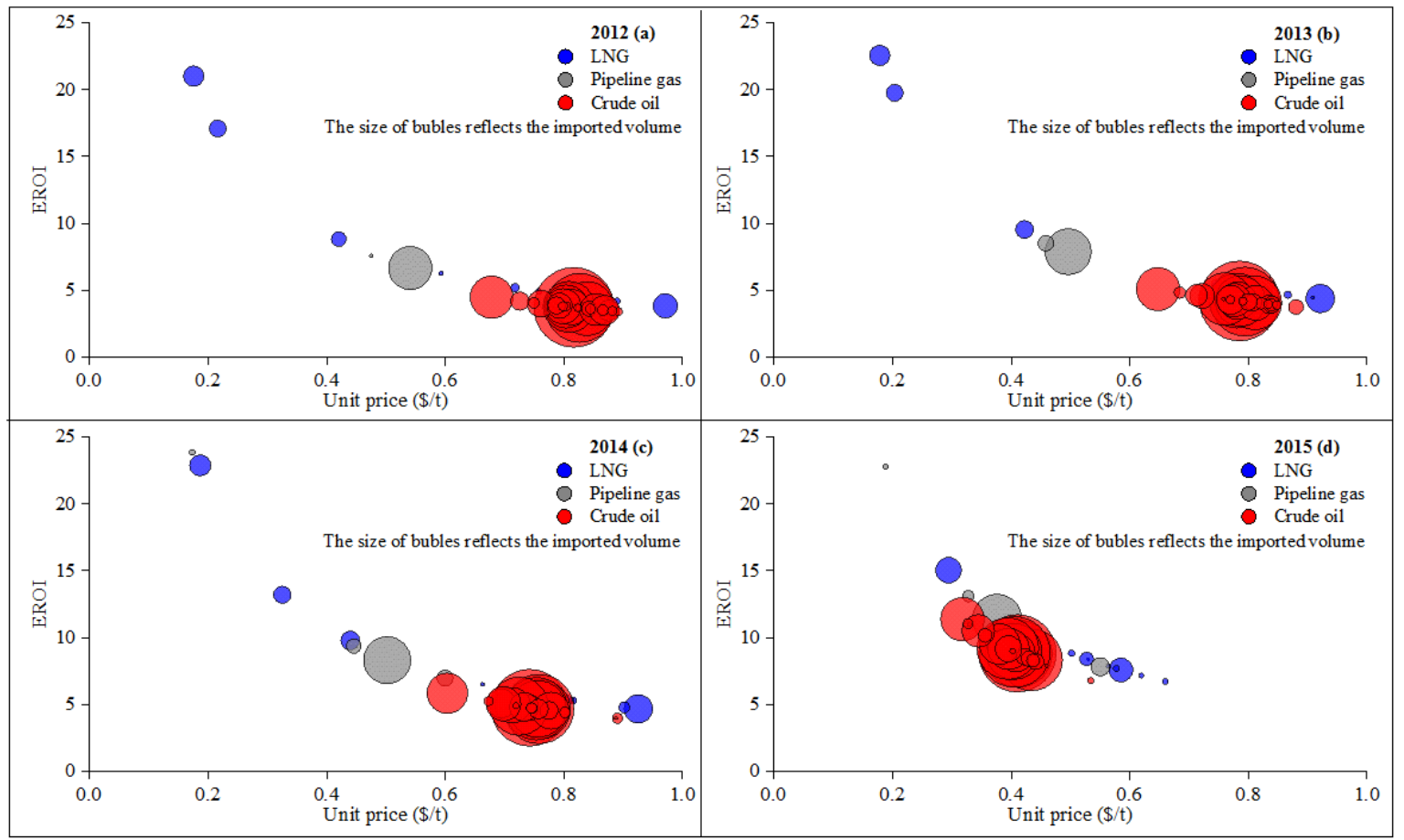

Fig. 14. The EROIs of different IOG producers. 
Appendix
Click here to download Supplementary Files: Appendix.docx 